University of Wollongong

Research Online

Australian Institute for Innovative Materials -

Papers

Australian Institute for Innovative Materials

$1-1-2015$

Porous nanoarchitectures of spinel-type transition metal oxides for electrochemical energy storage systems

\author{
Min-Sik Park \\ Korea Electronics Technology Institute (KETI), msp532@uow.edu.au \\ Jeonghun Kim \\ University of Wollongong, jhkim@uow.edu.au \\ Ki Jae Kim \\ Korea Electronics Technology Institute (KETI) \\ Jongwon Lee \\ Korea Institute of Energy Research \\ Jung Ho Kim \\ University of Wollongong, jhk@uow.edu.au
}

See next page for additional authors

Follow this and additional works at: https://ro.uow.edu.au/aiimpapers

Part of the Engineering Commons, and the Physical Sciences and Mathematics Commons

Research Online is the open access institutional repository for the University of Wollongong. For further information contact the UOW Library: research-pubs@uow.edu.au 


\title{
Porous nanoarchitectures of spinel-type transition metal oxides for electrochemical energy storage systems
}

\begin{abstract}
Transition metal oxides possessing two kinds of metals (denoted as AxB3-xO4, which is generally defined as a spinel structure; $\mathrm{A}, \mathrm{B}=\mathrm{Co}, \mathrm{Ni}, \mathrm{Zn}, \mathrm{Mn}, \mathrm{Fe}$, etc.), with stoichiometric or even non-stoichiometric compositions, have recently attracted great interest in electrochemical energy storage systems (ESSs). The spinel-type transition metal oxides exhibit outstanding electrochemical activity and stability, and thus, they can play a key role in realising cost-effective and environmentally friendly ESSs. Moreover, porous nanoarchitectures can offer a large number of electrochemically active sites and, at the same time, facilitate transport of charge carriers (electrons and ions) during energy storage reactions. In the design of spinel-type transition metal oxides for energy storage applications, therefore, nanostructural engineering is one of the most essential approaches to achieving high electrochemical performance in ESSs. In this perspective, we introduce spinel-type transition metal oxides with various transition metals and present recent research advances in material design of spinel-type transition metal oxides with tunable architectures (shape, porosity, and size) and compositions on the micro- and nano-scale. Furthermore, their technological applications as electrode materials for next-generation ESSs, including metal-air batteries, lithium-ion batteries, and supercapacitors, are discussed.
\end{abstract}

\section{Keywords}

oxides, transition, electrochemical, porous, type, systems, energy, spinel, storage, nanoarchitectures, metal

\section{Disciplines}

Engineering | Physical Sciences and Mathematics

\section{Publication Details}

Park, M., Kim, J., Kim, K., Lee, J., Kim, J. \& Yamauchi, Y. (2015). Porous nanoarchitectures of spinel-type transition metal oxides for electrochemical energy storage systems. Physical Chemistry Chemical Physics, 17 (46), 30963-30977.

\section{Authors}

Min-Sik Park, Jeonghun Kim, Ki Jae Kim, Jongwon Lee, Jung Ho Kim, and Yusuke Yamauchi 


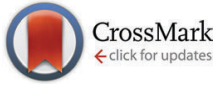

Cite this: Phys. Chem. Chem. Phys., 2015, 17, 30963

Received 3rd October 2015,

Accepted 27th October 2015

DOI: $10.1039 / c 5 c p 05936 d$

www.rsc.org/pccp

\section{Porous nanoarchitectures of spinel-type transition metal oxides for electrochemical energy storage systems}

\author{
Min-Sik Park, $\dagger^{\mathrm{a}}$ Jeonghun Kim, $\dagger^{\mathrm{b}}$ Ki Jae Kim, ${ }^{\mathrm{a}}$ Jong-Won Lee, ${ }^{* \mathrm{c}}$ Jung Ho Kim ${ }^{\star \mathrm{b}}$ \\ and Yusuke Yamauchi*de
}

\begin{abstract}
Transition metal oxides possessing two kinds of metals (denoted as $\mathrm{A}_{x} \mathrm{~B}_{3-x} \mathrm{O}_{4}$, which is generally defined as a spinel structure; $\mathrm{A}, \mathrm{B}=\mathrm{Co}, \mathrm{Ni}, \mathrm{Zn}, \mathrm{Mn}, \mathrm{Fe}$, etc.), with stoichiometric or even non-stoichiometric compositions, have recently attracted great interest in electrochemical energy storage systems (ESSs). The spinel-type transition metal oxides exhibit outstanding electrochemical activity and stability, and thus, they can play a key role in realising cost-effective and environmentally friendly ESSs. Moreover, porous nanoarchitectures can offer a large number of electrochemically active sites and, at the same time, facilitate transport of charge carriers (electrons and ions) during energy storage reactions. In the design of spinel-type transition metal oxides for energy storage applications, therefore, nanostructural engineering is one of the most essential approaches to achieving high electrochemical performance in ESSs. In this perspective, we introduce spinel-type transition metal oxides with various transition metals and present recent research advances in material design of spinel-type transition metal oxides with tunable architectures (shape, porosity, and size) and compositions on the micro- and nano-scale. Furthermore, their technological applications as electrode materials for next-generation ESSs, including metal-air batteries, lithium-ion batteries, and supercapacitors, are discussed.
\end{abstract}

\section{Introduction}

Efficient energy production and its trustworthy supply are the most urgent issues in our daily lives because of the rapid depletion of fossil fuels in recent years. There is no doubt that our energy consumption will increase continuously due to the widespread development and utilisation of various electricitythirsty products. Nevertheless, most electrical energy is still produced via combustion of fossil fuels with limited natural resources, which causes significant environmental pollution. Therefore, clean energy production from renewable energy sources such as solar, wind, and hydropower has been

\footnotetext{
${ }^{a}$ Advanced Batteries Research Center, Korea Electronics Technology Institute (KETI), 68 Yatap-dong, Bundang-gu, Seongnam 463-816, Republic of Korea

${ }^{b}$ Institute for Superconducting and Electronic Materials (ISEM), Australian Institute for Innovative Materials (AIIM), University of Wollongong; North Wollongong, NSW 2500, Australia. E-mail: jhk@uow.edu.au

${ }^{c}$ New and Renewable Energy Research Division, Korea Institute of Energy Research, 152 Gajeong-ro, Yuseong-gu, Daejeon 305-343, Republic of Korea.

E-mail: jjong277@kier.re.kr

${ }^{d}$ Faculty of Science and Engineering, Waseda University, 3-4-1 Okubo, Shinjuku, Tokyo 169-8555, Japan

${ }^{e}$ National Institute of Materials Science (NIMS), 1-1 Namiki, Tsukuba 305-0044, Japan. E-mail: yamauchi.yusuke@nims.go.jp

$\dagger$ Authors contributed equally to this work.
}

extensively studied by many researchers and scientists. ${ }^{1-5}$ At the same time, the high demand for portable electronic devices, electric vehicles (EVs), and large-scale stationary energy storage systems will further promote the rapid growth of energy storage markets.

In these circumstances, the electrochemical energy storage systems (ESSs), such as lithium-ion batteries, ${ }^{6-10}$ metal-air batteries, ${ }^{11-15}$ electrochemical capacitors, ${ }^{16-20}$ and redox flow batteries, ${ }^{21-25}$ have attracted worldwide attention due to their promising energy storage capabilities (Fig. 1). Most importantly, they can efficiently store electrical energy in the form of chemical energy and reversibly convert the stored energy into electrical energy without causing any pollution problems. In the near future, therefore, ESSs are expected to serve as a core technology that can improve the quality of human life by resolving environmental issues. The ESSs need to fulfill many requirements, for instance, high energy density, long-term stability, cost-effectiveness, design flexibility, good safety, and easy processability, which are determined by the physicochemical and electrochemical properties of the electroactive materials composing the ESSs. ${ }^{26-45}$ For this reason, many researchers have focused on the development of newly designed materials for sustainable energy storage applications. 
Among the various materials for ESSs, transition metal oxides with stoichiometric or even non-stoichiometric compositions, with a structure defined as the spinel structure (denoted as $\mathrm{A}_{x} \mathrm{~B}_{3-x} \mathrm{O}_{4}(\mathrm{~A}, \mathrm{~B}=\mathrm{Co}, \mathrm{Zn}, \mathrm{Ni}, \mathrm{Fe}, \mathrm{Cu}, \mathrm{Mn}$, etc.)), have recently attracted great interest due to their low cost, easy synthesis, high electrochemical activity and stability, and easy control of morphologies (details of a spinel structure will be discussed in the next section). Thus, many kinds of mixed metal oxide composites with a spinel structure have been explored and synthesised for practical use in ESS applications. In particular, the shape and size control of the spinel-type transition metal oxides has been regarded as a useful strategy to improve the electrochemical performance of ESSs. To date, various spineltype transition metal oxides with diverse shapes in micro- and nano-scale forms, including nanoparticles, ${ }^{46-48}$ nanoneedles, ${ }^{49}$ nanosheets, ${ }^{49-51}$ nanowires, ${ }^{52-56}$ nanorods,${ }^{57}$ nanocubes,${ }^{58,94}$ nanofibres, ${ }^{59}$ nanotubes, ${ }^{60,61}$ polyhedral structures, ${ }^{62,63,93}$ hierarchical structures, ${ }^{58,92}$ hollow structures ${ }^{58,64,97}$ and core-shell structures, ${ }^{65,96,97}$ have been synthesised and utilised as electroactive materials for ESSs. ${ }^{98}$

The porous nanoarchitectures constructed by various morphological strategies have proved to be highly desirable for energy storage materials used for practical ESSs. Generally, it is well-known that a porous structure enables bulk materials to have a greatly increased surface area. The tunability of the pore size and its distribution should also be considered together, since these parameters govern transport kinetics during charge/discharge processes. More importantly, a high surface area and appropriate pore size distribution can provide a large number of active sites for electrochemical redox reactions, as

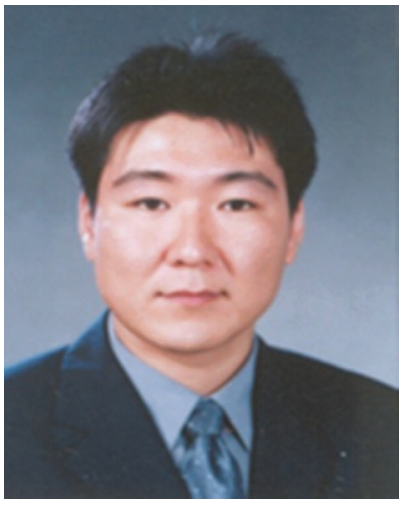

Min-Sik Park

Dr Min-Sik Park is a managerial researcher in the Advanced Batteries Research Center at the Korea Electronics Technology Institute (KETI). He received his $\mathrm{PhD}$ degree from the University of Wollongong (Australia) in 2008. As a visiting student, he also studied at the Tokyo Institute of Technology (TITECH) (20072008). Before he joined KETI, he was a research staff at the Samsung Advanced Institute of Technology (SAIT) (2008-2010). His current research is focused on advanced materials for energy storage applications such as lithium-ion batteries, lithium-ion capacitors, and post-lithium systems for next-generation energy storage devices.

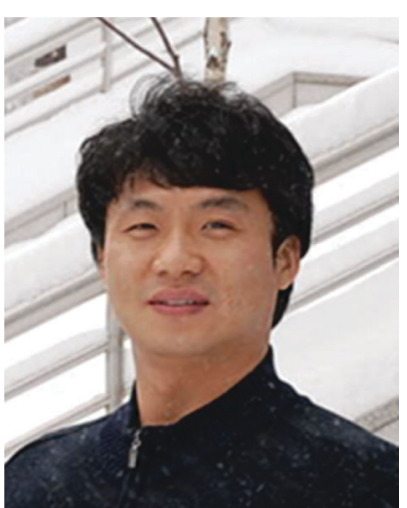

Ki Jae Kim
Dr Ki Jae Kim is a managerial researcher of Advanced Batteries Research Center at Korea Electronic Technology Institute (KETI). He received his $B S, M S$ and $P h D$ in the Department of Materials Science Engineering from Korea Advanced Institute of Science and Technology (KAIST) in 1999, 2001 and 2004. Prior to joining KETI, he worked as a senior researcher at LG Chemical Research Park, where he was working for the development of large size lithium ion batteries for hybrid and plug-in hybrid electric vehicles. His main research interests include the electrode for redox flow batteries and separators having good thermal properties for lithium ion batteries and lithium sulfur batteries.

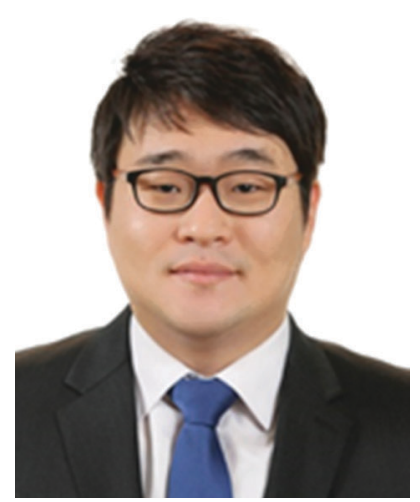

Jeonghun Kim
Dr Jeonghun Kim received his B.S. degree (2007) and $P h D$ degree (2012) in the Dept. of Chemical and Biomolecular Engineering at Yonsei University in Seoul, Korea. Until 2015, he worked at Dongjin Semichem Co., Ltd., in the Electronic Materials Division, $R \& D$ Center as a senior researcher for the synthesis, production, and applications of conductive polymers for electronic and energy devices. He is currently a postdoctoral fellow at the Institute for Superconducting and Electronic Materials (ISEM), Australian Institute for Innovative Materials (AIIM), University of Wollongong, Australia. His major research interest is the design and development of functional organic and inorganic materials for electronic and energy storage applications.

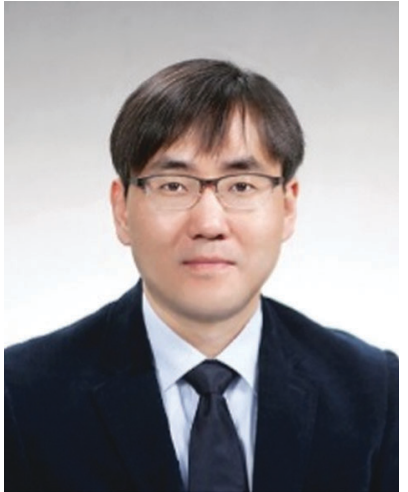

Jong-Won Lee
Dr Jong-Won Lee is a Principal Research Scientist at Korea Institute of Energy Research (KIER) and an Associate Professor at Korea University of Science and Technology. He received his $P h D$ (2005) in Materials Science from Korea Advanced Institute of Science and Technology, and then he worked as a Postdoctoral Researcher (2005) and as a Research Assistant Professor (2006-2008) at the University of South Carolina (USA). He was an $R \& D$ staff member (2008-2010) at Samsung Advanced Institute of Technology before joining KIER in 2010. His current research is focused on advanced functional materials for next-generation energy storage/conversion systems. 


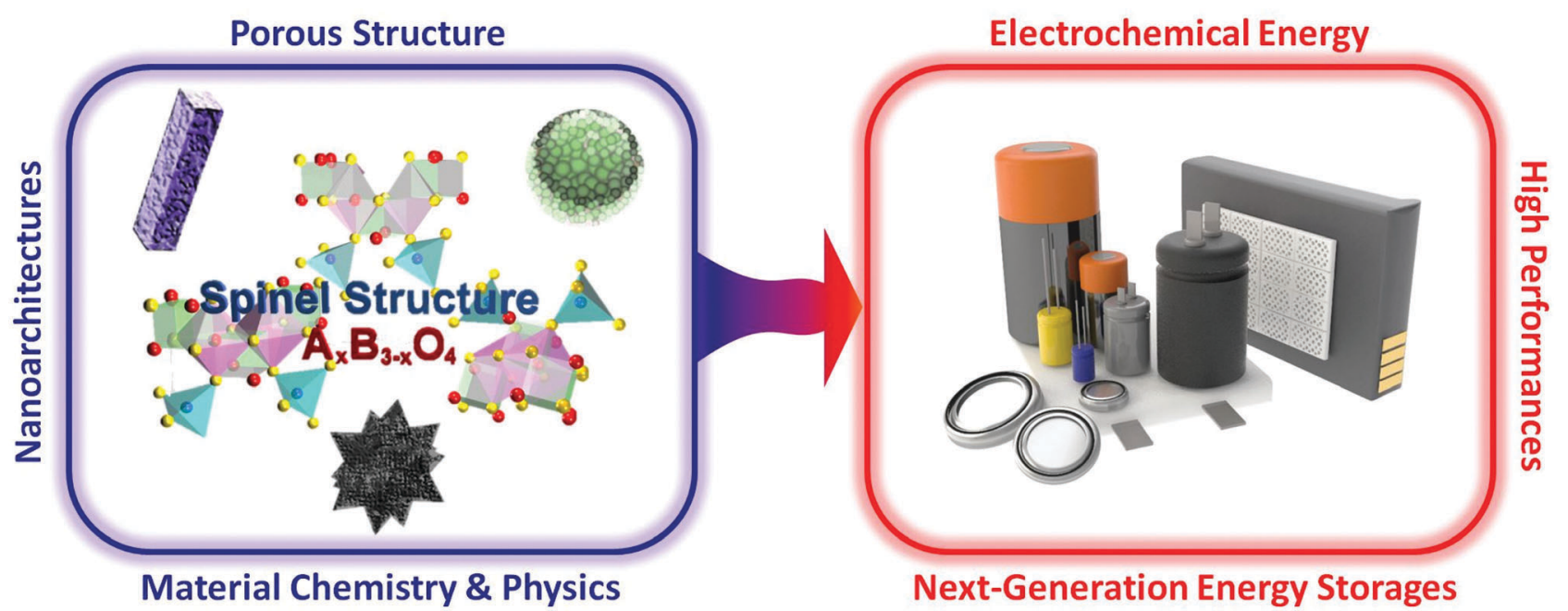

Fig. 1 Representative illustration of spinel-type transition-metal oxides based on various shapes and their applications in next-generation electrochemical energy storage systems (i.e., supercapacitors, lithium ion batteries, and metal-air batteries).

well as effective transportation paths for enhanced kinetics of electroactive species. To realise high-performance ESSs, therefore, it is of great importance to not only develop novel transition metal oxides with a spinel structure, but also to discover suitable morphological designs.

Recent research work has been intensively extended to the development of various mesoporous materials through different soft- or hard-framework/template methods. For example, the templating methods have been utilised for the creation of uniform pore sizes and their distribution, which are precisely changed by the original nanostructure of the templates that are used. Using a framework normally requires a multiple-step process, however. In addition, this method is not suitable for mass-production towards practical applications. Interestingly, mesoporous spinel-type transition metal oxides can be easily obtained without the templates mentioned above. For example, Hwang et al. ${ }^{66}$ reported a formation process for single- and double-walled hollow fibres via combustion reactions. The underlying formation mechanism is associated with the difference in migration rates of cationic elements and consequently different grain growth behaviours during calcination.

In this perspective, we introduce the spinel-type transition metal oxides and their practical applications in various ESSs (metal-air batteries, lithium-ion batteries, and supercapacitors).

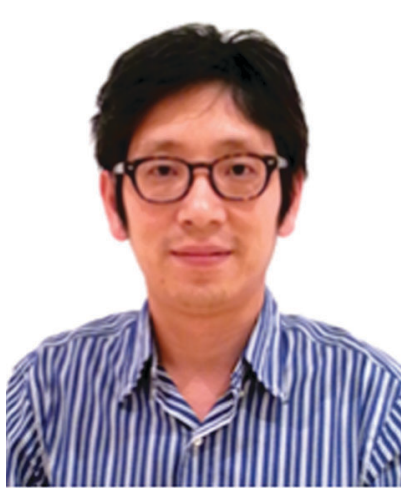

Jung Ho Kim
Prof. Jung Ho Kim is currently Associate Professor at the Institute for Superconducting and Electronic Materials (ISEM), Australian Institute for Innovative Materials (AIIM), University of Wollongong, Australia. He received his Bachelor's (1998), Master's (2000), and $P h D$ (2005) degrees from Sungkyunkwan University, Korea. He has published more than 150 papers in international refereed journals. He is currently acting as an editorial board member for Scientific Reports (Nature Publishing Group). His major research interest is the rational design of materials with one-, two-, and threedimensions towards energy storage and harvesting applications.

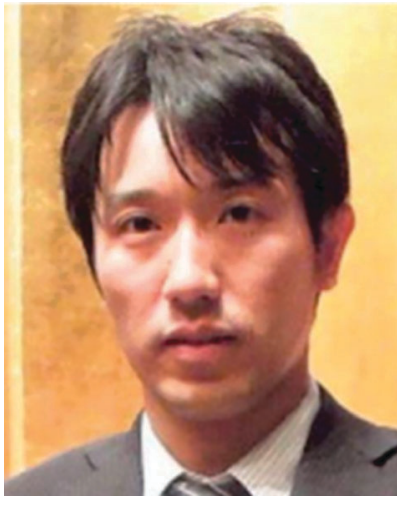

Yusuke Yamauchi
Prof. Yusuke Yamauchi received his bachelor's degree in 2003, master's degree in 2004, and PhD in 2007 from Waseda University in Japan. After receiving his $P h D$, he joined the National Institute for Materials Science (NIMS) as a permanent staff. In 2008, he started his own research group, the Inorganic Materials Laboratory. He has published more than 350 papers in international refereed journals with more than 9500 citations. He concurrently serves as a visiting professor at several universities (Tianjin University in China, Wollongong University in Australia, King Saud University in Saudi Arabia, and Waseda University in Japan) and as an associate editor of APL Materials published by the American Institute of Physics (AIP). His major research interest is the tailored design of novel nanoporous materials with various shapes and compositions towards practical applications. 
In particular, the beneficial roles of porous nanoarchitectures in achieving high electrochemical performance are addressed with deeper insights. This perspective will also give practical guidelines for surpassing the current problems that we are facing for developing advanced ESSs.

\section{General aspects of spinel-type transition metal oxides}

Ternary spinel-type transition metal oxides are described by the general formula of $\mathrm{AB}_{2} \mathrm{O}_{4}$, where $\mathrm{A}$ and $\mathrm{B}$ are divalent and trivalent metal cations, respectively. ${ }^{67}$ Also, the chemical formula for spinel structured metal oxides can be denoted as $\mathrm{A}_{x} \mathrm{~B}_{3-x} \mathrm{O}_{4}$ (A, B = Co, Zn, Ni, Fe, Cu, Mn, etc.). The spinel structure consists of a cubic close-packed array of oxide ions, in which one-eighth of the tetrahedral sites and one half of the octahedral sites are occupied by cations. ${ }^{68-70}$ The structure of $\mathrm{Co}_{3} \mathrm{O}_{4}$ spinel is illustrated as an example in Fig. 2a. The distribution of the cations between these two sites is highly dependent upon the nature of the cations incorporated into the structure. In normal spinels, the divalent $\mathrm{A}$ and trivalent $\mathrm{B}$ cations occupy the tetrahedral and octahedral sites, respectively, as in $\mathrm{Co}_{3} \mathrm{O}_{4}$, i.e., $\left[\mathrm{Co}^{2+}\right]\left[\mathrm{Co}^{3+}\right]_{2} \mathrm{O}_{4}$. In inverse spinels, on the other hand, half of the trivalent $\mathrm{B}$ cations reside on the tetrahedral sites, and the remaining trivalent $\mathrm{B}$ and divalent A cations occupy the octahedral sites as in $\mathrm{Fe}_{3} \mathrm{O}_{4}$, i.e., $\left[\mathrm{Fe}^{3+}\right]\left[\mathrm{Fe}^{3+} \mathrm{Fe}^{2+}\right] \mathrm{O}_{4}$.

Spinel-type transition metal oxides can accommodate a wide range of cations with more than one oxidation state between the tetrahedral and octahedral sites, and thus, their physical, chemical, and electrochemical properties are determined by the types of cations as well as the compositions and site occupancies. $^{71-73}$ In a recent study using first-principles calculations, for example, Ndione et al. examined the relationship between cation distribution (disorder) and electrical conductivity for the normal spinel $\mathrm{ZnCo}_{2} \mathrm{O}_{4}$ and the inverse spinel $\mathrm{NiCo}_{2} \mathrm{O}_{4}{ }^{74}$ Their key findings indicate the following: (i) $\mathrm{NiCo}_{2} \mathrm{O}_{4}$ exhibits higher conductivity than $\mathrm{ZnCo}_{2} \mathrm{O}_{4}$; and (ii) the p-type carrier density increases with increasing octahedral site-occupancy of the $\mathrm{A}$ atoms ( $\mathrm{Zn}$ or $\mathrm{Ni}$ ), leading to semiconducting behaviour in the normal spinel $\mathrm{ZnCo}_{2} \mathrm{O}_{4}$, but to half-metallic behaviour in the

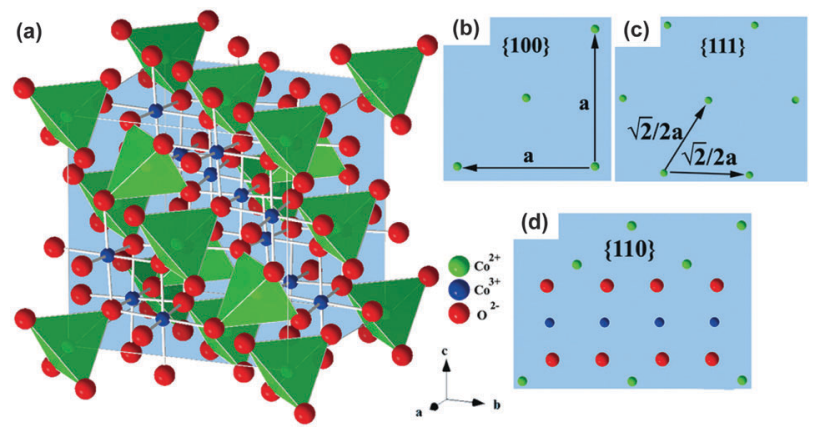

Fig. 2 (a) Crystal structure of normal spinel $\mathrm{CO}_{3} \mathrm{O}_{4}$ and (b-d) surface atomic configurations in the $\{100\},\{111\}$ and $\{110\}$ planes. Reprinted with permission from ref. 78. Macmillan Publishers Ltd. inverse spinel $\mathrm{NiCo}_{2} \mathrm{O}_{4}$. In addition to the electrical behaviour, the catalytic properties of spinel-type transition metal oxides towards chemical or electrochemical reactions (e.g., Co oxidation, oxygen reduction/evolution, and redox conversion of NO and CO mixtures) have been found to be determined by the nature of the surface, namely, the atomic arrangement and coordination on the oxide surface. ${ }^{75-80}$ Xiao et al. synthesised $\mathrm{Co}_{3} \mathrm{O}_{4}$ nanocrystals with different exposed surfaces on graphene sheets and studied the dependence of the electrocatalytic activity on the surface structure. ${ }^{78}$ The surface atomic configurations in the $\{100\},\{111\}$, and $\{110\}$ planes are shown in Fig. $2 b-d$, respectively. They found that the $\mathrm{Co}^{2+}$ ions on the surface serve as the catalytically active sites for electrochemical oxygen reduction in $0.1 \mathrm{M} \mathrm{KOH}$ and that the electrocatalytic activity depends on the detailed surface structure of the $\mathrm{Co}_{3} \mathrm{O}_{4}$ nanocrystals: namely, the activity increases in the order of $\{110\} \ll\{100\}<\{111\}$. As will be discussed later, numerous researchers have devoted their efforts to synthesizing spinel-type transition metal oxides and tailoring their properties for use in various fields, particularly in electrochemical energy storage applications, including metal-air batteries, lithiumion batteries, and supercapacitors.

As in the case of other oxides, the traditional synthesis methodology of spinel-type transition metal oxides is based on the solid-state route, i.e., formation of spinel-type transition metal oxides via thermal decomposition of metal precursors at high temperatures under oxidizing conditions. Such a solid state method, however, requires elevated temperatures and/or long synthesis time to produce the desired spinel structures. Generally, it leads to the formation of large crystallites with very low surface areas and porosity, which would make them unsuitable for use as electroactive materials for energy storage applications. Given that the electrochemical properties of spinel-type transition metal oxides are highly sensitive to their material characteristics, a large number of low-temperature synthesis procedures have been developed for the fabrication of spinel-type transition metal oxides with controlled composition, crystal structures, surface morphologies, and porous structures. $^{50,81-88}$ Although Section 3 provides details of the preparation of spinel-type transition metal oxides and their applications in specific ESSs, here, we highlight the most recent progress in the synthesis of spinel-type transition metal oxides with controlled phases and porous/morphological characteristics.

Chen and his co-workers reported a synthesis methodology for $\mathrm{Co}_{3-x} \mathrm{Mn}_{x} \mathrm{O}_{4}$ spinel nanoparticles with tailored structural symmetry and compositions via a solution-based route. ${ }^{89}$ As shown in Fig. 3, this synthesis process involves a room-temperature oxidation precipitation of $\mathrm{Mn} / \mathrm{Co}$ salts with $\mathrm{NH}_{3} \mathrm{H}_{2} \mathrm{O}$ in an air atmosphere, followed by crystallisation into spinels at $180{ }^{\circ} \mathrm{C}$. The nanosized spinel crystallites $(\sim 10 \mathrm{~nm})$ were synthesised, and, more importantly, their crystallographic phase (cubic or tetragonal) and composition could be independently controlled by adjusting the molar ratio of $\mathrm{Co} / \mathrm{Mn}$ precursors. The tetragonal spinel was obtained in a composition range of $1<x<3$, whereas the cubic form was synthesised for $0<x<2$.

It is of great importance to develop strategies to fabricate nanostructured spinel-type transition metal oxides with tailored 
(a)
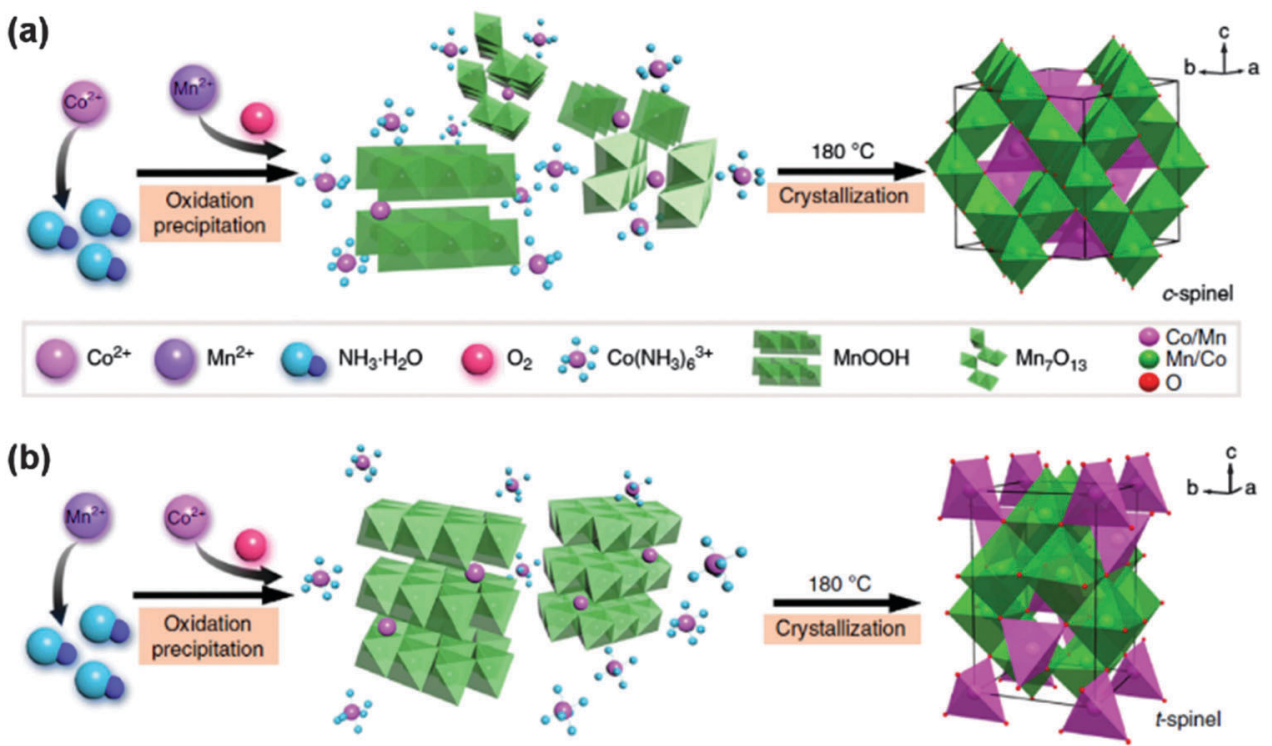

Fig. 3 Controlled synthesis of (a) cubic and (b) tetragonal spinel $\mathrm{Co}_{3-x} \mathrm{Mn}_{x} \mathrm{O}_{4}$ through a two-step process involving oxidation precipitation and crystallisation. Reprinted with permission from ref. 89. Macmillan Publishers Ltd.

morphologies and porous structures. Rosen et al. prepared a $\mathrm{Co}_{3} \mathrm{O}_{4}$ spinel that has an ordered mesoporous structure, very high surface area, and highly crystalline spinel walls. ${ }^{90} \mathrm{Mg}$-substituted $\mathrm{Co}_{3} \mathrm{O}_{4}$ with three-dimensional ordered mesoporous structure was first fabricated through a hard-templating method, followed by an $\mathrm{Mg}^{2+}$ leaching process. In the latter step, approximately a third of the $\mathrm{Mg}$ cations were removed, leading to the formation of a highly porous spinel oxide structure. The materials had a uniform pore size distribution $(\sim 3.7 \mathrm{~nm})$ and a surface area as high as $102 \mathrm{~m}^{2} \mathrm{~g}^{-1}$. Ordered mesoporous spinels of $\mathrm{MCo}_{2} \mathrm{O}_{4}(\mathrm{M}=\mathrm{Cu}$, $\mathrm{Mn}$, and $\mathrm{Ni}$ ) with crystalline walls were also synthesised by Zhu and Gao. ${ }^{91}$ In this work, a nanocasting pathway was developed using concentrated metal nitrate solutions as precursors and mesoporous silica SBA-15 as the hard template. The precursor solutions were infiltrated into the pore channels of the silica template, and then, mesoporous spinel-type transition metal oxides with high surface areas $\left(91-129 \mathrm{~m}^{2} \mathrm{~g}^{-1}\right)$ and large pore volumes $\left(0.35-0.41 \mathrm{~cm}^{3} \mathrm{~g}^{-1}\right)$ were obtained after a mild thermal treatment and removal of the silica template (Fig. $4 \mathrm{a}$ and b).

Wu et al. discovered a method for preparing mesoporous $\mathrm{Ni}_{0.3} \mathrm{Co}_{2.7} \mathrm{O}_{4}$ with hierarchical structure. No template or surfactant is used, and hence, the procedure is simple and suitable for large-scale synthesis. ${ }^{92} \mathrm{~A}$ metal oxalate hydrate precursor $\left(\mathrm{Ni}_{0.1} \mathrm{Co}_{0.9} \mathrm{C}_{2} \mathrm{O}_{4} \cdot n \mathrm{H}_{2} \mathrm{O}\right)$ with hierarchical structure was first synthesised via precipitation in the presence of oxalate ions and then was calcined to form $\mathrm{Ni}_{0.3} \mathrm{Co}_{2.7} \mathrm{O}_{4}$. The synthesised particles showed a highly porous texture and a dandelion-like morphology composed of numerous rod-like subunits, in which the rod-like building blocks were composed of nanoparticles with sizes of a few tens of nanometers (Fig. 4c and d). Zhou and co-workers reported a simple and scalable strategy to fabricate highly porous $\mathrm{Zn}_{x} \mathrm{Co}_{3-x} \mathrm{O}_{4}$ hollow polyhedra composed of nanosized building blocks (Fig. 4e and f). ${ }^{93}$ The method involves a morphology-inherited and thermolysis-induced transformation of hetero-bimetallic zeolitic imidazolate frameworks (ZIFs). That is, the polyhedral ZIFs were first obtained by the reaction of 2-methylimidazole with divalent $\mathrm{Zn}$ ions and $\mathrm{Co}$ ions in a methanol solution at room temperature, and then, porous $\mathrm{Zn}_{x} \mathrm{Co}_{3-x} \mathrm{O}_{4}$ hollow polyhedra with a high surface area $\left(\sim 65.6 \mathrm{~m}^{2} \mathrm{~g}^{-1}\right)$ were obtained through a thermally induced oxidative decomposition process. Interestingly, the porous hollow structure exhibited a bimodal pore size distribution at $\sim 4$ and $\sim 9 \mathrm{~nm}$. In addition, Guo et al. reported the preparation of hollow "crossed" $\mathrm{NiCO}_{2} \mathrm{O}_{4}$ nanocubes through the fabrication of amorphous hollow $\left(\mathrm{NiCo}_{x}\right) \mathrm{O}(\mathrm{OH})$ nanoboxes combined with subsequent calcination (Fig. $4 \mathrm{~g}$ and $\mathrm{h}) .{ }^{94}$

In recent years, a non-equilibrium heat-treatment process has been widely used to fabricate core-shell structured and/or hollow metal oxide spheres. ${ }^{58,95,96} \mathrm{Li}$ et al. synthesised porous cubic spinel $\mathrm{Mn}_{1.5} \mathrm{Co}_{1.5} \mathrm{O}_{4}$ core-shell microspheres composed of a $\sim 400 \mathrm{~nm}$-thick shell and a core with a diameter of $\sim 2.5 \mu \mathrm{m}$ (Fig. $4 \mathrm{i}$ and j). ${ }^{65}$ First, $\mathrm{Mn}_{0.5} \mathrm{Co}_{0.5} \mathrm{CO}_{3}$ microspheres were produced by a urea-assisted solvothermal process. Then, the $\mathrm{Mn}_{1.5} \mathrm{Co}_{1.5} \mathrm{O}_{4}$ spheres with the core-shell structure were fabricated through thermal decomposition. The formation of the core-shell structure was explained in terms of heterogeneous contraction caused by the non-equilibrium heat-treatment process: (i) the oxide shell is first formed on the surface of the carbonate core due to a temperature gradient during heating; and (ii) when the temperature reaches a target value and becomes constant, the inner carbonate core starts to transform into the oxide, resulting in a core-shell oxide microsphere. Furthermore, Shen et al. developed a strategy for the synthesis of $\mathrm{NiCo}_{2} \mathrm{O}_{4}$ hollow spheres with complex interior structures. ${ }^{97}$ The spinel-type transition metal oxides were prepared by a two-step process: in the first step, uniform nickel-cobalt glycerate spheres used as the precursor were prepared by a solvothermal method, and then, the resulting solid spheres were converted to $\mathrm{NiCo}_{2} \mathrm{O}_{4}$ 


\section{(1)}
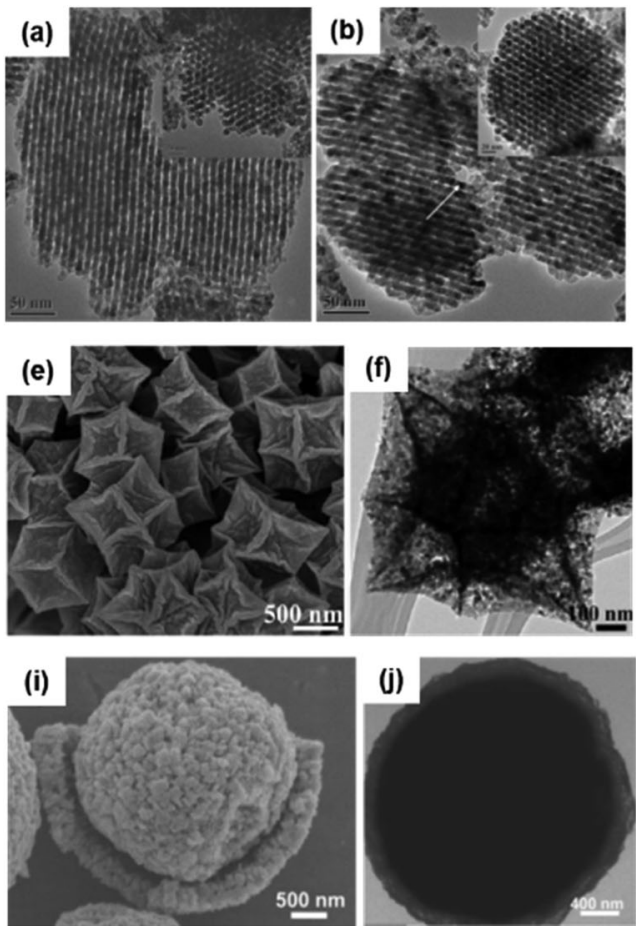
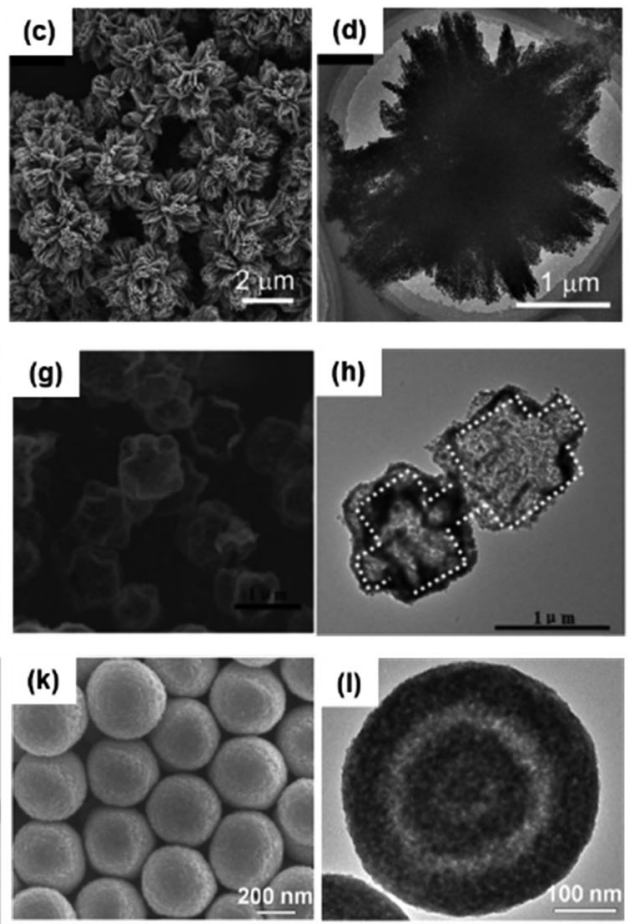

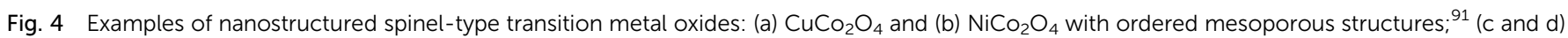

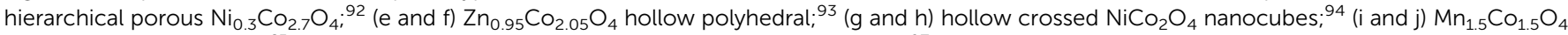

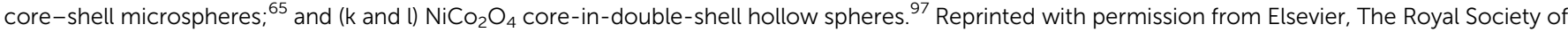
Chemistry, American Chemical Society, and Wiley.

"core-in-double shell" hollow spheres by a non-equilibrium heat-treatment process (Fig. 4k and l).

\section{Porous spinel-type transition metal oxides for energy storage applications}

Global demand for energy storage technology is expected to grow rapidly due to increasing concerns about replacing fossil fuels with renewable energy use. In this respect, the role of ESSs is becoming more crucial than ever. To build advanced ESSs, it is essential to develop advanced materials, because energy storage capability is highly dependent on material characteristics. ${ }^{16,99}$ From the viewpoint of materials, porous ternary spinel-type transition metal oxides $\left(\mathrm{A}_{x} \mathrm{~B}_{3-x} \mathrm{O}_{4}\right)$ have attracted considerable attention as promising energy storage materials, which are applicable for metal-air batteries, lithium-ion batteries, and supercapacitors. Such systems show great promise in terms of energy densities and power densities amongst the commercially available ESSs. ${ }^{99,100}$ Recent approaches to further enhancing the electrochemical performance of those systems are encouraged by the development of nanostructured materials, which will be the most important key to success for developing advanced ESSs. ${ }^{101}$

\subsection{Metal-air batteries (MABs)}

Recently, concerns about energy and environmental issues have triggered extensive research and development activities on battery-powered electric vehicles (EVs). It is generally agreed that, to compete with gasoline automobiles, EVs should have driving ranges of $>500 \mathrm{~km}$, which requires batteries with an energy density of $>500 \mathrm{~W} \mathrm{~h} \mathrm{~kg}{ }^{-1} \cdot{ }^{102,103}$ The performance of today's batteries, such as lithium-ion batteries (LIBs), is still far behind the requirements for long-range EVs, however. The metal-air battery (MAB) is an advanced energy storage technology for EVs that has the potential to surpass LIBs in terms of energy density. ${ }^{102-109}$ Basically, this battery consists of (i) a metal anode (Li, $\mathrm{Zn}, \mathrm{Al}, \mathrm{Mg}$, etc.), (ii) an air-breathing cathode, and (iii) an ion-conducting electrolyte sandwiched between the two electrodes, as shown in Fig. 5a. During discharge, the battery generates electricity via an oxidation reaction of the metal anode and a reduction reaction of oxygen $\left(\mathrm{O}_{2}\right)$ on the cathode. The reverse reactions, i.e., metal reduction and oxygen evolution, occur upon charge. When considering energy density and reversibility, Zn-air and Li-air batteries are the major candidates that can enable long-range EVs: in particular, a $\mathrm{Li}$-air cell has a theoretical energy density of $11680 \mathrm{~W} \mathrm{~h} \mathrm{~kg}^{-1}$, which is comparable to that of gasoline. ${ }^{104,108}$

The critical challenges facing MAB technology include low round-trip efficiency as well as poor rate capability (low power density) and poor cyclability (Fig. 5b), which are mainly caused by slow kinetics of the oxygen reduction reaction (ORR) and the oxygen evolution reaction (OER) on the cathode. ${ }^{104,106,107,109-111}$ Therefore, various types of catalytic materials have been incorporated into the cathode to promote the ORR and OER in aqueous or non-aqueous (organic) electrolytes. ${ }^{111,112}$ Preciousmetal-based catalysts have been recognised to be excellent 
(a)
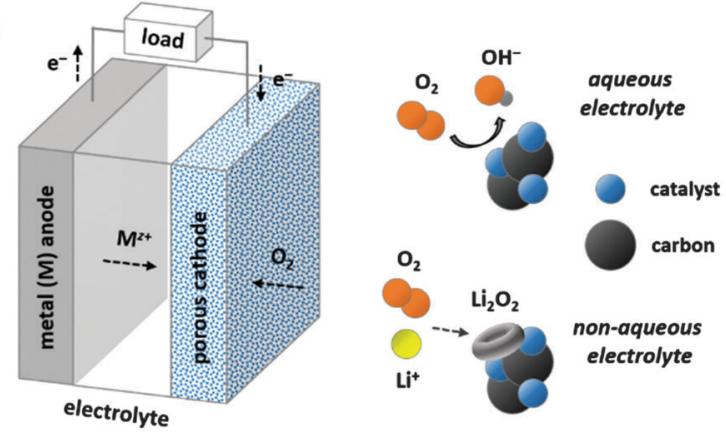

(b)

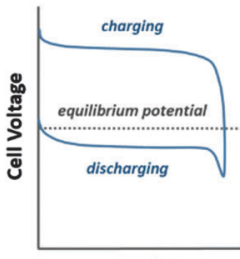

Capacity
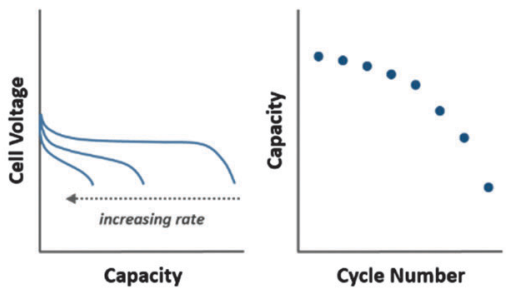

Fig. 5 Schematic diagrams of (a) the operation mechanism of a metal-air battery $(\mathrm{MAB})$, along with the oxygen reduction reaction on the cathode in aqueous and non-aqueous electrolytes, and (b) technical problems typically observed in MABs, including low round-trip efficiency, poor rate-capability, and poor cyclability.

candidates; ${ }^{113-115}$ although it is desirable to exclude those elements that have low abundance and are quite expensive. In the search for more affordable catalytic materials, a number of researchers have devoted their effort to developing metal oxide catalysts with high activity and to utilising them in MABs. ${ }^{116-126}$ In particular, spinel-type transition metal oxides have attracted great attention as catalytic materials for MABs due to their relatively low cost and high activity. Spinel-type transition metal oxides based on Co, Mn and/or Ni have been reported to exhibit strong bi-functionality towards the ORR and OER in aqueous alkaline electrolytes: ${ }^{11,89,127}$

$$
\text { ORR-OER: } \mathrm{O}_{2}+2 \mathrm{H}_{2} \mathrm{O}+4 \mathrm{e}^{-} \leftrightarrow 4 \mathrm{OH}^{-} \text {(aqueous) }
$$

The intrinsic electrocatalytic properties of spinel-type transition metal oxides are highly dependent upon the composition, crystal structure, and distribution/oxidation state of the metal cations. ${ }^{11,89,127}$ Rios et al. examined the composition-activity relationship of cubic spinel $\mathrm{Mn}_{x} \mathrm{Co}_{3-x} \mathrm{O}_{4}(0 \leq x \leq 1)$ towards the ORR and OER in $1 \mathrm{M} \mathrm{KOH} .{ }^{127}$ They proposed that Mn redox couples serve as the main catalytic sites for the ORR, and thus, the ORR activity increases with increasing Mn content $(x)$. On the other hand, the OER activity becomes lower at higher $x$ values, partly due to the inhibiting role of $\mathrm{Mn}$ in the $\mathrm{OH}^{-}$ oxidation. Cheng et al. performed a combined experimental and theoretical study to understand the structure-dependent activity of the cubic and tetragonal Co-Mn-O spinels. ${ }^{11}$ According to their study, the oxygen binding ability of the Co and Mn defect sites on the surface plays a key role in determining the catalytic activity of the cubic and tetragonal spinels. The Co defect site can bind oxygen more strongly than the Mn defect site. Compared to the tetragonal spinel, therefore, the surface of the cubic spinel provides more strengthened bonds between the metal and adsorbed $\mathrm{O}_{2}$ species, which makes the cubic spinel more active towards the ORR. The lower OER activity of the cubic spinel can be understood based on the fact that the OER is the reverse process of the ORR.

In addition to the composition and crystal structure, the morphological characteristics of the spinel-type transition metal oxides have a strong impact on their ability to catalyse the ORR and OER. Great effort has been put into fabricating porous, nanostructured catalysts with many active sites and favourable reaction pathways for applications in aqueous MABs. As an example, $\mathrm{Ma}$ et al. reported spinel-type $\mathrm{MnCo}_{2} \mathrm{O}_{4}$ catalysts with multiporous structures, which were fabricated via a solvothermal route. ${ }^{128}$ The catalysts were composed of nanoparticle aggregates with hollow interiors and mesopores, and hence, they have a large number of available reaction sites and facilitate the diffusion of reactants during the ORR and OER. As a result, the synthesised $\mathrm{MnCo}_{2} \mathrm{O}_{4}$ catalysts displayed considerable bi-functionality towards the ORR and OER in $0.1 \mathrm{M} \mathrm{KOH}$.

One-dimensional (1D) fibrous catalysts can offer additional benefits to MAB cathodes, including high surface area-tovolume ratios, short diffusion lengths in the radial direction, and low flow resistance through fibre bundles. In this context, Jung et al. synthesised 1D porous spinel nanofibres $\left(\mathrm{MnCo}_{2} \mathrm{O}_{4}\right.$ and $\mathrm{CoMn}_{2} \mathrm{O}_{4}$ ) using an electrospinning technique combined with heat-treatment and applied them as cathode catalysts for aqueous $\mathrm{Zn}$-air batteries (Fig. 6). ${ }^{129}$ It was found that the $1 \mathrm{D}$ spinel catalysts are able to considerably improve the round-trip efficiency of $\mathrm{Zn}$-air batteries (i.e., reduce discharge-charge voltage gaps by $\sim 440 \mathrm{mV}$ compared to the catalyst-free carbon cathode) (Fig. 6b), which is attributed to their high catalytic activity towards the ORR and OER during discharge and charge, respectively. Also, Prabu et al. demonstrated that 1D spinel $\mathrm{NiCo}_{2} \mathrm{O}_{4}$ catalysts with hierarchical nanostructures outperformed conventional precious metal catalysts in terms of the voltage gap of the $\mathrm{Zn}$-air battery: $0.84 \mathrm{~V}\left(1 \mathrm{D} \mathrm{NiCo} \mathrm{O}_{4}\right)$ vs. $1.16 \mathrm{~V}$ (Pt), $1.01 \mathrm{~V}(\mathrm{Ru})$, and $0.92 \mathrm{~V}(\mathrm{Ir}) .^{130}$

The ORR-OER electrochemistry is of crucial importance in MABs with non-aqueous (organic) electrolytes, especially in Li-air batteries: ${ }^{111,131-135}$

$$
\begin{gathered}
\text { ORR: } \mathrm{O}_{2}+\mathrm{e}^{-} \rightarrow \mathrm{O}_{2}^{-} \text {(formation of } \mathrm{LiO}_{2} \text { intermediates) } \\
\text { (non-aqueous) } \\
\text { OER: } \mathrm{Li}_{2} \mathrm{O}_{2} \rightarrow 2 \mathrm{Li}^{+}+\mathrm{O}_{2}+2 \mathrm{e}^{-} \text {(non-aqueous) }
\end{gathered}
$$

A unique aspect of $\mathrm{Li}-\mathrm{O}_{2}$ electrochemistry in non-aqueous electrolytes is that the discharge and charge processes involve the formation (ORR) and decomposition (OER) of solid $\mathrm{Li}_{2} \mathrm{O}_{2}$ species in the cathode, respectively, which is insoluble and has electrically insulating bulk properties. The sluggish kinetics of $\mathrm{Li}_{2} \mathrm{O}_{2}$ formation and decomposition severely limits battery performance.

Spinel-type transition metal oxides have been widely used as cathode catalysts in an attempt to improve the electrochemical performance of non-aqueous Li-air batteries. There is, however, disagreement regarding their catalytic role in promoting 
(a)

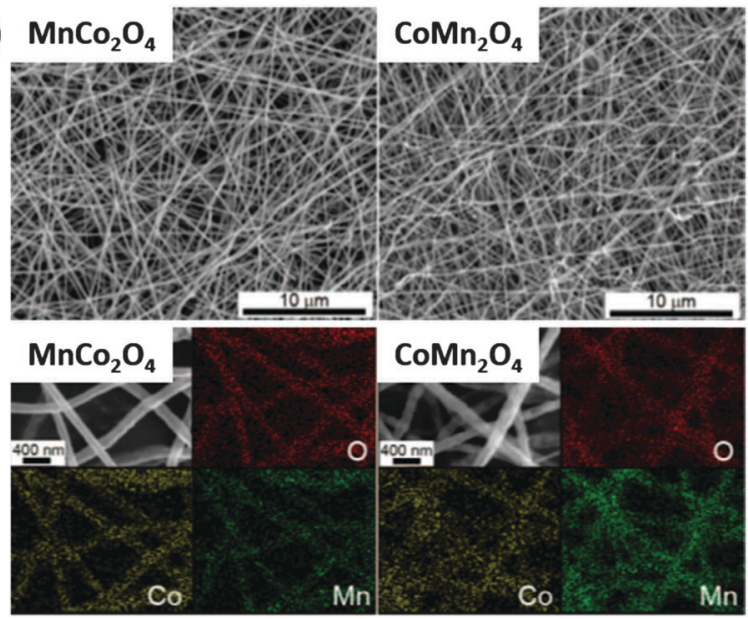

(b)

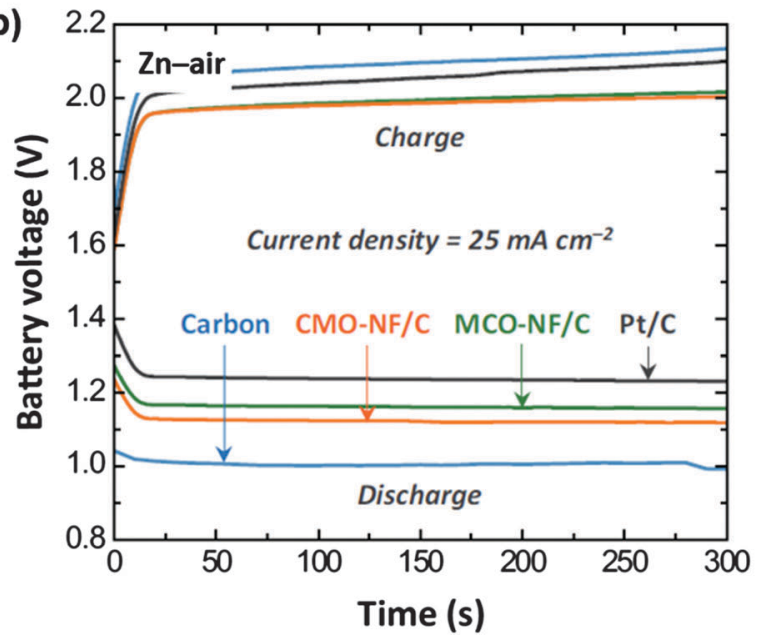

Fig. 6 (a) $1 \mathrm{D} \mathrm{MnCO}_{2} \mathrm{O}_{4}(\mathrm{MCO})$ and $\mathrm{COMn}_{2} \mathrm{O}_{4}$ (CMO) spinel nanofibres (NFs) fabricated by an electrospinning technique combined with heattreatment and (b) galvanostatic discharge-charge curves of the aqueous $\mathrm{Zn}$-air batteries assembled with various cathodes. Reprinted with permission from ref. 129. Macmillan Publishers Ltd.

the ORR and OER. In some reports, ${ }^{136-139}$ for instance, $\mathrm{Co}_{3} \mathrm{O}_{4}$ appeared to serve as an efficient catalyst to reduce charge potentials and improve cyclability, whereas in another, ${ }^{140}$ it is inactive but acts as a promoter to enhance surface transport of $\mathrm{Li}_{x} \mathrm{O}_{2}$ species rather than as a classic electron-transfer catalyst. To examine the catalytic effect, Zhu et al. carried out firstprinciples studies on the $\mathrm{Co}_{3} \mathrm{O}_{4}$ surfaces and suggested that the $\mathrm{Co}_{3} \mathrm{O}_{4}$ surface with Lewis acid sites is capable of reducing charge voltages due to facilitated electron transfer from $\mathrm{Li}_{2} \mathrm{O}_{2}$ to the catalytic surface and a reduced $\mathrm{O}_{2}$ desorption barrier. ${ }^{141}$ Using a carbon-free, oxide-only cathode, moreover, Lee and his co-workers have provided clear evidence that $\mathrm{Co}_{3} \mathrm{O}_{4}$ and other spinel-type transition metal oxides have the ability to catalyse $\mathrm{O}_{2}$ reduction and $\mathrm{Li}_{2} \mathrm{O}_{2}$ decomposition in an ether-based electrolyte. ${ }^{142,143}$ Given that $\mathrm{Li}_{2} \mathrm{O}_{2}$ should be stored within the cathode, three-dimensional (3D) architectures of the cathode would play a significant role in determining the electrochemical performance of non-aqueous Li-air batteries. In addition to
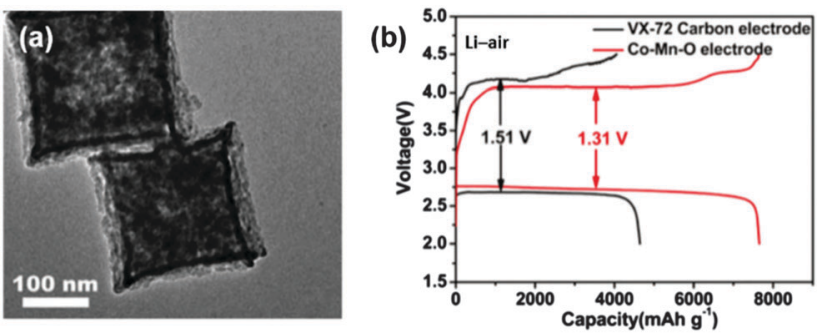

Fig. 7 (a) Porous nanocube catalyst of the mixed tetragonal ( $\mathrm{Co}, \mathrm{Mn}$ ) $(\mathrm{Co}, \mathrm{Mn})_{2} \mathrm{O}_{4}$ and cubic $\mathrm{MnCO}_{2} \mathrm{O}_{4}$ spinels and (b) the electrochemical performance of the non-aqueous $\mathrm{Li}$-air batteries with the catalyst-free and catalyst-containing cathode. Reproduced with permission from ref. 145. Royal Society of Chemistry.

discovering the best catalyst composition with high intrinsic activity, therefore, much of the focus has been on controlling 3D catalyst structures. 3D cathode structures must be designed to have a large number of active sites, high porosity and optimum pore sizes, and tailored porous structures suitable for mass transport. ${ }^{144}$ In fact, properly tailored 3D structured spinel oxide catalysts, including porous cubes, ${ }^{145,146}$ rods,${ }^{147,148}$ wires, ${ }^{149}$ fibres, ${ }^{150}$ flakes, ${ }^{151-153}$ platelets, ${ }^{146}$ and spheres, ${ }^{154}$ have led to improved battery performance. Zhang et al. synthesised porous spinel nanocubes from metal-organic frameworks (Fig. 7a). ${ }^{145}$ The nanocube-like precursors were first prepared by a selfassembly method and then annealed to make oxides in which the tetragonal $(\mathrm{Co}, \mathrm{Mn})(\mathrm{Co}, \mathrm{Mn})_{2} \mathrm{O}_{4}$ and cubic $\mathrm{MnCo}_{2} \mathrm{O}_{4}$ spinels coexist. When incorporated into the cathode of a Li-air battery, the resulting catalyst increased both the capacity and the roundtrip efficiency (Fig. 7b), which are traced back to the large pore volume $\left(\sim 0.22 \mathrm{~cm}^{3} \mathrm{~g}^{-1}\right)$ and the high specific surface area $\left(\sim 110 \mathrm{~m}^{2} \mathrm{~g}^{-1}\right)$, as well as the high intrinsic activity of the Mn- and Co-based spinel.

A recent study by Li et al. showed that, in addition to the surface area and porosity, controlling the pore sizes of the catalytic materials is of vital importance for high-performance Li-air batteries. ${ }^{93}$ In this study, 3D ordered mesoporous $\mathrm{NiFe}_{2} \mathrm{O}_{4}$ materials with controlled pore sizes (5.0-25.1 nm) were synthesised using KIT- 6 as the hard template. The results demonstrated improved specific capacity, rate capability, and cyclability of the Li-air battery with increasing mesopore size of the catalyst, which could be explained in terms of higher utilisation of larger mesopores during the ORR and OER. Other specific examples demonstrating the beneficial role of controlled architectures in non-aqueous $\mathrm{Li}$-air batteries include mesoporous $\mathrm{NiCO}_{2} \mathrm{O}_{4}$ nanoflakes, ${ }^{151}$ two-dimensional (2D) mesoporous $\mathrm{ZnCo}_{2} \mathrm{O}_{4}$ nanoflakes, ${ }^{153}$ mesoporous spherical shell-structured $\mathrm{Co}_{3} \mathrm{O}_{4},{ }^{154}$ and ordered mesoporous $\mathrm{NiFe}_{2} \mathrm{O}_{4} \cdot{ }^{155}$

As briefly discussed above, the spinel-type transition metal oxide catalysts with controlled porous structures have been known to show high bi-functional catalytic properties towards the ORR and OER in both aqueous and non-aqueous electrolytes, thereby improving the electrochemical performance of MABs. While continued effort should go into identifying highly active spinel catalysts, future research should also be devoted to developing bi-functional catalysts that can support 
stable cycling operation in the highly corrosive environments of MABs.

\subsection{Lithium-ion batteries (LIBs)}

Spinel lithium-manganese oxide $\left(\mathrm{LiMn}_{2} \mathrm{O}_{4}\right)$ has been widely used as a popular cathode material for commercial LIBs owing to its intrinsic advantages of a high operating potential, low environmental impact, and low cost. Above all, the high-power characteristic of $\mathrm{LiMn}_{2} \mathrm{O}_{4}$, resulting from its three-dimensional crystal structure, makes it suitable for high-power applications such as power tools and electric vehicles. The spinel $\mathrm{LiMn}_{2} \mathrm{O}_{4}$ cathode is plagued, however, by the drawback of undesirable capacity loss during cycling, which is mainly attributed to: (i) $\mathrm{Mn}$ dissolution via a disproportionation reaction $\left(2 \mathrm{Mn}^{3+} \rightarrow \mathrm{Mn}^{2+}+\mathrm{Mn}^{4+}\right)$ and (ii) structural transformation (cubic $\rightarrow$ tetragonal) induced by Jahn-Teller distortion of high-spin $\mathrm{Mn}^{3+}$ in the structure. ${ }^{156}$ To overcome these limitations of spinel $\mathrm{LiMn}_{2} \mathrm{O}_{4}$, extensive effort has been devoted to various structural modifications such as surface coatings, cation doping, and morphological control. One of the most effective ways to improve the cycling performance and ratecapability of spinel $\mathrm{LiMn}_{2} \mathrm{O}_{4}$ is morphological modification on the nanoscale through nanotechnology. Nanostructured spinel $\mathrm{LiMn}_{2} \mathrm{O}_{4}$ has shown a remarkably improved electrochemical performance in comparison with bulk spinel $\mathrm{LiMn}_{2} \mathrm{O}_{4} \cdot{ }^{157-165}$ In particular, porous spinel $\mathrm{LiMn}_{2} \mathrm{O}_{4}$ nanostructures showed great promise for further improvement of their electrochemical performance during long-term use. ${ }^{166}$ The porous structure generally offers a large active surface, short diffusion lengths of charge carriers (i.e., $\mathrm{Li}^{+}$), and sufficient electrolyte pathways, which are responsible for improving $\mathrm{Li}^{+}$mobility in the given structure. In practice, porous spinel $\mathrm{LiMn}_{2} \mathrm{O}_{4}$ microspheres, which are constructed from nanometer-sized primary particles, exhibited excellent rate capability and long-term stability, with a specific discharge capacity of $98 \mathrm{~mA} \mathrm{~h} \mathrm{~g}{ }^{-1}$ and the corresponding capacity retention of $80 \%$ for up to 500 cycles, even at a high current density of $20 \mathrm{C}^{162}$ Cheng et al. also reported porous $\mathrm{LiMn}_{2} \mathrm{O}_{4}$ nanorods synthesised by using porous $\mathrm{Mn}_{2} \mathrm{O}_{3}$ nanorods as a self-supported template obtained by thermal decomposition of the manganese oxalate precursor. An initial discharge capacity of $105 \mathrm{~mA} \mathrm{~h} \mathrm{~g}{ }^{-1}$ could be delivered at a current density of $10 \mathrm{C}$, and a capacity retention of about $90 \%$ was obtained after 500 cycles, as shown in Fig. 8. ${ }^{156}$ These results support the argument that porous nanostructures are favourable for fast $\mathrm{Li}^{+}$intercalation with good structural stability. On the other hand, various porous spinel structures have been proposed as anode materials for LIBs as well. Porous spinel zinccobalt oxide $\left(\mathrm{Zn}_{x} \mathrm{Co}_{3-x} \mathrm{O}_{4}\right)$ composed of nanosized building blocks features a morphology-inherited and thermolysis-induced transformation of heterobimetallic zeolitic imidazolate frameworks (ZIF) (Fig. 9). It exhibited a higher reversible capacity ( $>1000 \mathrm{~mA} \mathrm{~h}^{-1}$ ) and much better rate capability in comparison with the bulk spinel structure. ${ }^{93}$ Hwang et al. also reported the potential use of mesoporous hollow manganese-cobalt oxide $\left(\mathrm{MnCo}_{2} \mathrm{O}_{4}\right)$ and cobalt-manganese oxide $\left(\mathrm{CoMn}_{2} \mathrm{O}_{4}\right)$ nanofibres with spinel structures prepared by an electrospinning method
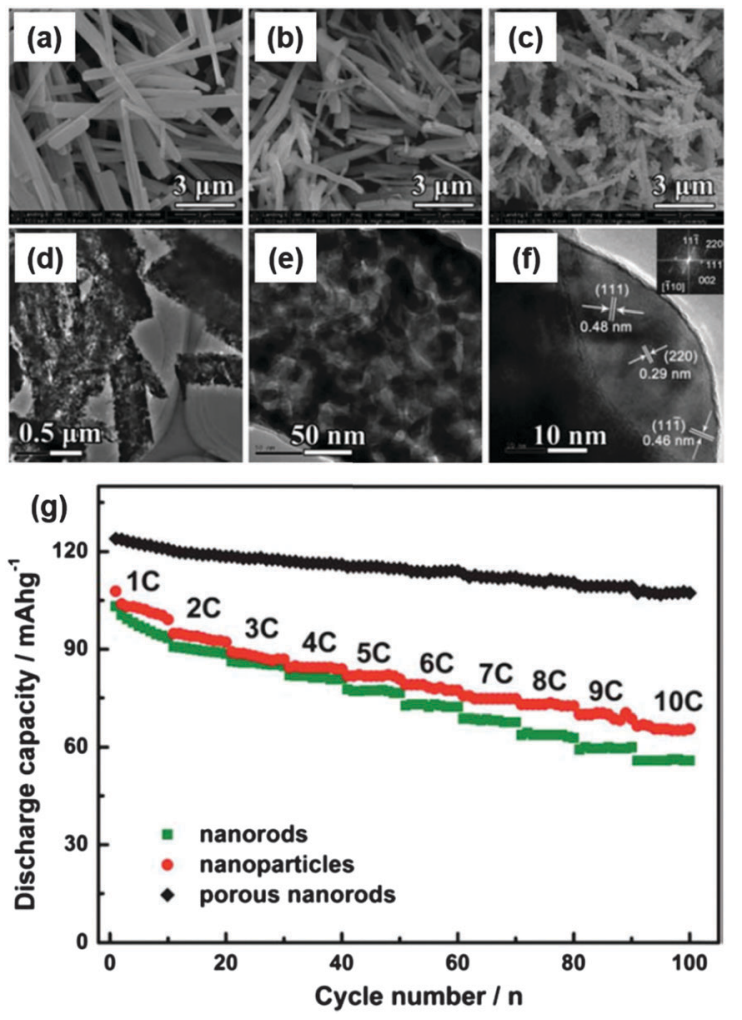

Fig. 8 SEM micrographs of the as-prepared (a) $\mathrm{MnC}_{2} \mathrm{O}_{4}$ nanorods, (b) porous $\mathrm{Mn}_{2} \mathrm{O}_{3}$ nanorods, and (c) porous spinel $\mathrm{LiMn}_{2} \mathrm{O}_{4}$ nanorods. (d) Low-magnification and (e) high-magnification TEM images of the porous spinel $\mathrm{LiMn}_{2} \mathrm{O}_{4}$ nanorods. (f) HRTEM image and the corresponding FFT pattern (inset) of a single nanoparticle in the porous nanorods. (g) Discharge capacities of the synthesised porous nanorods, nanorods, and nanoparticles cycling sequentially from $1 \mathrm{C}$ to $10 \mathrm{C}$ for every 10 cycles at each discharge rate. Reproduced with permission from ref. 156. Royal Society of Chemistry.

combined with controlled heat-treatment. Owing to their unique nanostructures, featuring high porosity and large active surface area, they offer high $\mathrm{Li}^{+}$storage capability and rapid $\mathrm{Li}^{+}$movement in the structures. ${ }^{66}$ Similarly, the advantages of porous $\mathrm{ZnCo}_{2} \mathrm{O}_{4}$ nanotubes as a promising $\mathrm{Li}^{+}$storage material also have been reported by Luo et al. ${ }^{60}$ The porous nanotubes could promote $\mathrm{Li}^{+}$ transport into the electrode by allowing sufficient channels, leading to a high rate capability. ${ }^{60}$ In a continuing effort, $\mathrm{CoMn}_{2} \mathrm{O}_{4}$ microspheres assembled from porous nanosheets were proposed as an anode material for LIBs. The open space between neighbouring nanosheets can ensure sufficient electrolyte pathways as well as easy diffusion of $\mathrm{Li}^{+}$in the structure, as shown in Fig. 10. As a result, this material can achieve good cyclability and high rate capability. ${ }^{164}$ Positive effects of the porous spinel structure were also found in mesoporous lithium titanate $\left(\mathrm{Li}_{4} \mathrm{Ti}_{5} \mathrm{O}_{12}\right)$ with a spinel structure, which showed improved $\mathrm{Li}^{+}$storage capability and rate capability because of the mesopores integrated into the material. According to Haetge et al., mesoporous spinel $\mathrm{Li}_{4} \mathrm{Ti}_{5} \mathrm{O}_{12}$ thin film electrodes not only exhibited enhanced highly reversible capacity at short charging times, but also were able to maintain stable cycling performance at a current density as high as 64 C. ${ }^{165}$ As demonstrated by many research groups, it is advantageous to 
(a)

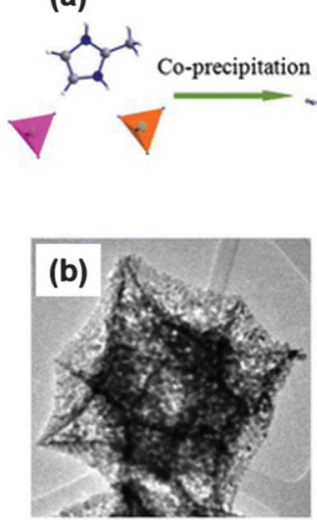

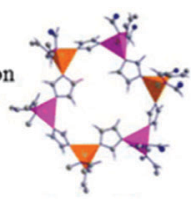

$\mathrm{Zn}-\mathrm{Co}$-ZIFs

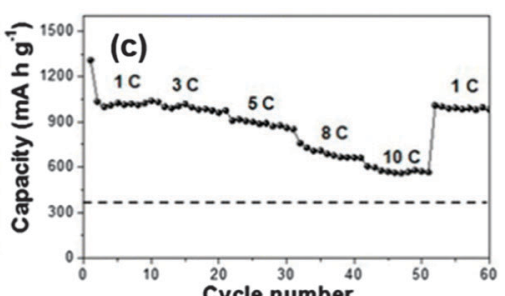

Fig. 9 (a) Schematic illustration of the synthesis of hollow spinel $\mathrm{Zn}_{x} \mathrm{CO}_{3-x} \mathrm{O}_{4}$, (b) TEM image of hollow spinel $\mathrm{Zn}_{x} \mathrm{CO}_{3-x} \mathrm{O}_{4}$, and (c) cycle performance of the hollow spinel $\mathrm{Zn}_{x} \mathrm{CO}_{3-x} \mathrm{O}_{4}$ anode for lithium ion batteries. Reproduced with permission from ref. 93. American Chemical Society
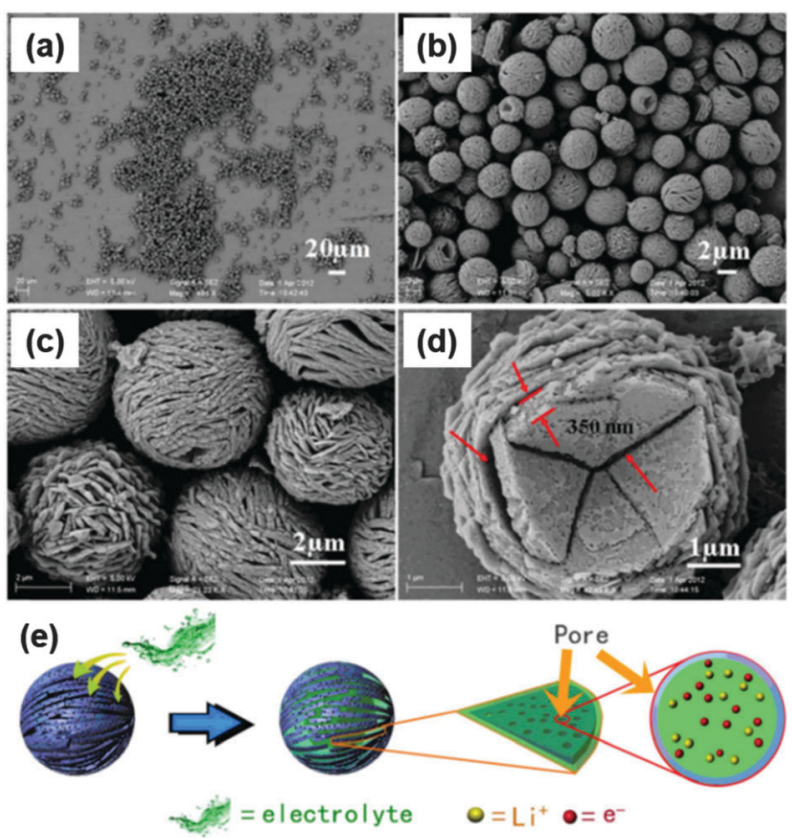

Fig. 10 Morphological and structural analysis of spinel $\mathrm{CoMn}_{2} \mathrm{O}_{4}$ hierarchical microspheres. (a)-(d) SEM images of the spinel $\mathrm{CoMn}_{2} \mathrm{O}_{4}$ hierarchical microspheres at different magnifications. (e) Schematic illustration of the diffusion of electrolytes, electrons and $\mathrm{Li}$ ions. The electrolyte can diffuse into the inner part of spinel $\mathrm{CoMn}_{2} \mathrm{O}_{4}$ hierarchical mesoporous microspheres easily from the open space between neighbouring nanosheets. Hierarchical structure can ensure that every nanosheet contact electrolyte, the pores between $\mathrm{CoMn}_{2} \mathrm{O}_{4}$ nanoparticles can ensure that $\mathrm{Li}^{+}$and electron diffuse with little resistance. Reproduced with permission from ref. 164. Macmillan Publishers Ltd.

form porous spinel nanostructures for improving the electrochemical performance by expanding the active surface area and reducing the dimensions of the materials. Even if the electrochemical performance of spinel $\mathrm{LiMn}_{2} \mathrm{O}_{4}$ can be effectively improved by forming porous nanostructures, the problem is its

relatively low electrode density. This technical issue should be further considered before practical use.

\subsection{Supercapacitors (SCs)}

SCs are probably one of the most important energy storage systems, which can be used in various applications requiring rapid charge/discharge performance within vehicles, cranes, and elevators for regenerative braking and short-term energy storage, as well as back-up power. ${ }^{28,166}$ There are two types of SCs: electric double-layer capacitors (EDLCs) and pseudocapacitors, which are generally classified by their electrode materials because the electrochemical performance of SCs could be determined by the electrode materials. In EDLCs, carbon-based materials, such as activated carbon, mesoporous carbon, carbon nanotubes, and graphene, are widely used for non-faradaic double-layer charging reactions of active species. In contrast, pseudocapacitors can allow redox reactions by employing additional redox active materials such as conducting polymers (e.g., polyaniline, polypyrrole, and polythiophene) or metal oxides (e.g., $\mathrm{MnO}_{2}, \mathrm{~V}_{2} \mathrm{O}_{5}$, and $\mathrm{RuO}_{2}$ ), leading to a higher energy density than EDLCs. With these strategies, researchers are still looking for advanced materials to further improve the energy density of SCs. Porous spinel nanostructures are also promising candidates for use in SCs, because transition metals can be used to construct spinel structures, which generally have multiple oxidation states, leading to additional pseudocapacitance in the SCs. ${ }^{167}$ Recently, it has been proved that the striking network-like spinel $\mathrm{NiCo}_{2} \mathrm{O}_{4}$ framework simultaneously provides a $3 \mathrm{D}$ continuous electron transport expressway, convenient electrolyte penetration-diffusion, and a large electrodeelectrolyte interface. ${ }^{168}$ As a result, the unique network-like spinel $\mathrm{NiCo}_{2} \mathrm{O}_{4}$ electrode features a SC of $587 \mathrm{~F} \mathrm{~g}^{-1}$ at a current density of $2 \mathrm{~A} \mathrm{~g} \mathrm{~g}^{-1}$, and could deliver up to $518 \mathrm{~F} \mathrm{~g}^{-1}$ at the high current density of $16 \mathrm{~A} \mathrm{~g}^{-1}$. From a similar viewpoint, Shakir et al. reported hierarchical porous spinel $\mathrm{NiCo}_{2} \mathrm{O}_{4}$ nanoflakes synthesised by a chemical precipitation method, which showed a high specific capacitance $\left(1270 \mathrm{~F} \mathrm{~g}^{-1}\right)$, and excellent rate capability and cycling stability. ${ }^{169}$ Interestingly, Du et al. proposed $\mathrm{NiCo}_{2} \mathrm{O}_{4}$ arrays constructed from interconnected ultrathin nanosheets $(10 \mathrm{~nm})$ with many interparticle pores. The porous feature of the $\mathrm{NiCo}_{2} \mathrm{O}_{4}$ nanosheets increases the amount of electroactive sites and facilitates the electrolyte penetration. ${ }^{170}$ As shown in Fig. 11, hence, the $\mathrm{NiCo}_{2} \mathrm{O}_{4} /$ carbon fabric (CF) composite exhibited a high specific capacitance of $2658 \mathrm{~F} \mathrm{~g}^{-1}$ at a current density of $2 \mathrm{~A} \mathrm{~g}^{-1}$ with good rate performance and superior cycle life. ${ }^{170}$ It should be noted that the specific capacitance and rate capability of SCs can be significantly affected by the physicochemical characteristics of the materials (e.g., surface area, porosity, and morphology). On the other hand, the feasibility of porous spinel nanostructures has been examined in hybrid capacitors composed of a transition metal oxide cathode and an activated carbon anode for further improved energy density without a significant power loss. In such systems, the feasibility of porous spinel $\mathrm{LiMn}_{2} \mathrm{O}_{4}$ as a cathode material has also been examined by many researchers. Unlike the conventional electric double-layer capacitor (EDLC), the porous 

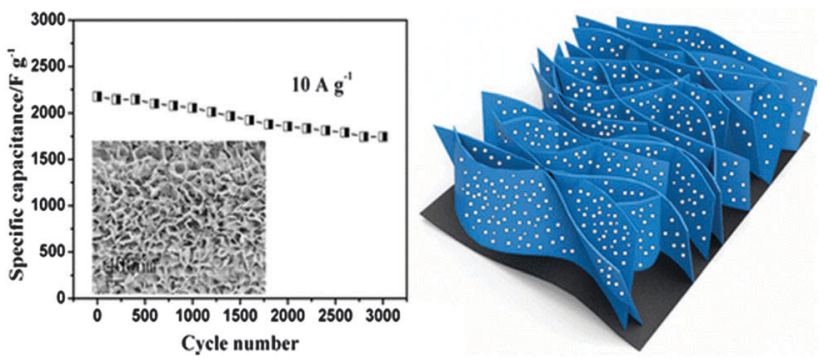

Fig. 11 Cycling performance (left) of ultrathin porous spinel $\mathrm{NiCO}_{2} \mathrm{O}_{4}$ nanosheet arrays on flexible carbon fabric (CF) for supercapacitors. SEM image (inset) and schematic illustration (right) of ultrathin porous spinel $\mathrm{NiCO}_{2} \mathrm{O}_{4}$ nanosheet arrays. Reproduced with permission from ref. 170 . American Chemical Society.

spinel $\mathrm{LiMn}_{2} \mathrm{O}_{4}$ cathode allows a faradaic reaction based on the intercalation process of $\mathrm{Li}^{+}$in the system, which is essential for improved energy density of the capacitors. ${ }^{171}$ Considering the superior rate capability of porous spinel $\mathrm{LiMn}_{2} \mathrm{O}_{4}$, it is the most suitable candidate among the various transition metal oxides. Furthermore, the presence of a large proportion of mesopores in the structure is beneficial for facilitating diffusion of charge carriers within the interior of the carbon framework and hence for reducing the resistance. Note that a fundamental understanding of this presently unique material is essential in order to determine its key physical and chemical behaviour. This understanding might lead to a commercially viable hybrid capacitor that does not contain any noble metal. ${ }^{172}$ As we discussed in this section, porous spinel structures have great potential as energy storage materials in this research field. The porous structures have several advantages for boosting electrochemical reactions by minimizing diffusion distances of active species and accelerating the kinetic processes. Furthermore, they provide extra free space for enhancing the mobility of active species and alleviating the structural strain. As a result, the electrochemical performance of spinel structures can be further enhanced. Therefore, many porous spinel structures have been designed, and their feasibility has been thoroughly examined for practical use in various ESSs, owing to their structural superiority. ${ }^{173}$

\section{Concluding remarks and perspectives}

In this perspective, we have summarised the advantages of mesoporous spinel-type transition metal oxides and their direct applications as electrodes for various energy storage systems (ESSs). Nanostructured porous spinel-type transition metal oxides exhibit remarkable energy storage capabilities and sustainability. Understanding the correlation between physicochemical properties and electrochemical activity of the spinel-type transition metal oxides is essential for developing a suitable formulation to further improve their energy storage capability. In this respect, many researchers have explored various potential candidates with a spinel structure and developed suitable synthesis processes to examine their feasibility.
In this perspective, we introduced various synthesis methodologies for the preparation of spinel-type transition metal oxides with unique nanoarchitectures and discussed their composition-structure-property relationships determined using various analytical tools. Specific emphasis was placed on the following: (i) how the composition and atomic arrangements on the surface and/or within the bulk as well as morphologies and porous structures could be tailored by precise control of synthesis parameters, and (ii) how those physicochemical characteristics could affect the electrochemical reactions of spinel-type transition metal oxides used in ESSs, e.g., catalytic oxygen reduction/evolution, lithium intercalation (lithiation), and pseudocapacitive redox reaction. As described in this perspective, ultra-high surface area and good permeability are typical characteristics of porous nanostructures, directly affecting the electrochemical redox reactions of energy storage materials. The expanded surface area is responsible for increasing the density of active sites, and the open space between internal frameworks allows for fast mobility of charge carriers. Owing to these benefits, the mesoporous spinel-type transition metal oxides have shown efficient, and even more stable electrochemical performance compared with bulk spinel-type transition metal oxides.

Since the energy storage capability of ESSs is highly dependent on the characteristics of materials (i.e., microstructure, morphology, and composition), it is necessary to first develop robust and high-performance materials. In the pursuit of advanced ESSs, more attention should be paid to the correlation between material design and electrochemical performance of the materials. ${ }^{174-180}$ In this respect, the recent progress presented here in the material design of spinel-type transition metal oxides with tunable shapes, porosity, sizes, and compositions will provide practical guidelines for building highly reliable and high performance energy storage materials.

\section{Acknowledgements}

M.-S. Park and J.-W. Lee acknowledge financial support from the R\&D Convergence Program (National Research Council of Science \& Technology, Project No. CAP-14-2-KITECH) of the Republic of Korea.

\section{Notes and references}

1 Z. Yang, J. Zhang, M. C. W. Kintner-Meyer, X. Lu, D. Choi, J. P. Lemmon and J. Liu, Chem. Rev., 2011, 111, 3577.

2 W. Seung, M. K. Gupta, K. Y. Lee, K.-S. Shin, J.-H. Lee, T. Y. Kim, S. Kim, J. Lin, J. H. Kim and S.-W. Kim, ACS Nano, 2015, 9, 3501.

3 X. Fang and H. Peng, Small, 2015, 11, 1488.

4 J. Lin, L. Zhao, Y.-U. Heo, L. Wang, F. H. Bijarbooneh, A. J. Mozer, A. Nattestad, Y. Yamauchi, S. X. Dou and J. H. Kim, Nano Energy, 2015, 11, 557.

5 J. Lin, Y.-U. Heo, A. Nattestad, Z. Sun, L. Wang, J. H. Kim and S. X. Dou, Sci. Rep., 2014, 4, 5769.

6 Z. Wang, L. Zhou and X. W. Lou, Adv. Mater., 2012, 24, 1903. 
7 H. Wu, G. Yu, L. Pan, N. Liu, M. T. McDowell, Z. Bao and Y. Cui, Nat. Commun., 2013, 4, 1943.

8 Y. Yang, G. Yu, J. J. Cha, H. Wu, M. Vosgueritchian, Y. Yao, Z. Bao and Y. Cui, ACS Nano, 2011, 5, 9187.

9 G. Jeong, J.-G. Kim, M.-S. Park, M. Seo, S. M. Hwang, Y.-U. Kim, Y.-J. Kim, J. H. Kim and S. X. Dou, ACS Nano, 2014, 8, 2977.

10 R. Zhang, Y. Du, D. Li, D. Shen, J. Yang, Z. Guo, H. Liu, A. A. Elzatahry and D. Zhao, Adv. Mater., 2014, 26, 6749.

11 F. Cheng, J. Shen, B. Peng, Y. Pan, Z. Tao and J. Chen, Nat. Chem., 2011, 3, 79.

12 E. Yoo and H. Zhou, ACS Nano, 2011, 5, 3020.

13 X. Cao, J. Wu, C. Jin, J. Tian, P. Strasser and R. Yang, ACS Catal., 2015, 5, 4890.

14 Z. Cui, L. Li, A. Manthiram and J. B. Goodenough, J. Am. Chem. Soc., 2015, 137, 7278.

15 L. Dai, Y. Xue, L. Qu, H.-J. Choi and J.-B. Baek, Chem. Rev., 2015, 115, 4823.

16 P. Simon and Y. Gogotsi, Nat. Mater., 2008, 7, 845.

17 M. Pramanik, Y. Tsujimoto, V. Malgras, S. X. Dou, J. H. Kim and Y. Yamauchi, Chem. Mater., 2015, 27, 1082.

18 R. R. Salunkhe, Y. Kamachi, N. L. Torad, S. M. Hwang, Z. Sun, S. X. Dou, J. H. Kim and Y. Yamauchi, J. Mater. Chem. A, 2014, 2, 19848.

19 B. Anothumakkool, R. Soni, S. N. Bhange and S. Kurungot, Energy Environ. Sci., 2015, 8, 1339.

20 M. M. Islam, S. H. Aboutalebi, D. Cardillo, H. K. Liu, K. Konstantinov and S. X. Dou, ACS Cent. Sci., 2015, 1, 206.

21 K. J. Kim, M.-S. Park, Y.-J. Kim, J. H. Kim, S. X. Dou and M. Skyllas-Kazacos, J. Mater. Chem. A, 2015, 3, 16913.

22 K. J. Kim, S.-W. Lee, T. Yim, J.-G. Kim, J. W. Choi, J. H. Kim, M.-S. Park and Y.-J. Kim, Sci. Rep., 2014, 4, 6906.

23 K. J. Kim, M. S. Park, J. H. Kim, U. Hwang, N. J. Lee, G. Jeong and Y. J. Kim, Chem. Commun., 2012, 48, 5455.

24 K. J. Kim, Y.-J. Kim, J. H. Kim and M.-S. Park, Mater. Chem. Phys., 2011, 131, 547.

25 J. G. Lee, J. H. Park and Y. G. Shul, Nat. Commun., 2014, 5, 4045.

26 J. Liu, N. P. Wickramaratne, S. Z. Qiao and M. Jaroniec, Nat. Mater., 2015, 14, 763.

27 H. Kim, G. Jeong, Y.-U. Kim, J.-H. Kim, C.-M. Park and H.-J. Sohn, Chem. Soc. Rev., 2013, 42, 9011.

28 K. Naoi, W. Naoi, S. Aoyagi, J.-I. Miyamoto and T. Kamino, Acc. Chem. Res., 2013, 46, 1075.

29 A. Manthiram, Y. Fu, S.-H. Chung, C. Zu and Y.-S. Su, Chem. Rev., 2014, 114, 11751.

30 V. Aravindan, J. Gnanaraj, Y.-S. Lee and S. Madhavi, Chem. Rev., 2014, 114, 11619.

31 M.-H. Ryou, Y. M. Lee, J.-K. Park and J. W. Choi, Adv. Mater., 2011, 23, 3066.

32 M.-H. Ryou, J. Kim, I. Lee, S. Kim, Y. K. Jeong, S. Hong, J. H. Ryu, T.-S. Kim, J.-K. Park, H. Lee and J. W. Choi, Adv. Mater., 2013, 25, 1517.

33 M. Ling, Y. Xu, H. Zhao, X. Gu, J. Qiu, S. Li, M. Wu, X. Song, C. Yan, G. Liu and S. Zhang, Nano Energy, 2015, 12, 178.
34 S.-J. Park, H. Zhao, G. Ai, C. Wang, X. Song, N. Yuca, V. S. Battaglia, W. Yang and G. Liu, J. Am. Chem. Soc., 2015, 137, 2565.

35 C. X. Guo, M. Wang, T. Chen, X. W. Lou and C. M. Li, Adv. Energy Mater., 2011, 1, 736.

36 L. Zhang, L. Zhang, L. Chai, P. Xue, W. Hao and H. Zheng, J. Mater. Chem. A, 2014, 2, 19036.

37 Y. Zhong, M. Yang, X. Zhou and Z. Zhou, Mater. Horiz., 2015, 2, 553.

38 K. Zhang, X. Han, Z. Hu, X. Zhang, Z. Tao and J. Chen, Chem. Soc. Rev., 2015, 44, 699.

39 Q. Zhang, E. Uchaker, S. L. Candelaria and G. Cao, Chem. Soc. Rev., 2015, 42, 3018.

40 S. Zhai, W. Jiang, L. Wei, H. E. Karahan, Y. Yuan, A. K. Ng and Y. Chen, Mater. Horiz., 2015, 2, 598.

41 D. P. Dubal, O. Ayyad, V. Ruiz and P. Gómez-Romero, Chem. Soc. Rev., 2015, 44, 1777.

42 H. Wang and H. Dai, Chem. Soc. Rev., 2013, 42, 3088.

43 X. Hu, W. Zhang, X. Liu, Y. Mei and Y. Huang, Chem. Soc. Rev., 2015, 44, 2376.

44 Q. Zhang, E. Uchaker, S. L. Candelaria and G. Cao, Chem. Soc. Rev., 2013, 42, 3127.

45 L. Borchardt, M. Oschatz and S. Kaskel, Mater. Horiz., 2014, 1, 157.

46 Y. Q. Wu, X. Y. Chen, P. T. Ji and Q. Q. Zhou, Electrochim. Acta, 2011, 56, 7517.

47 Y. Yang, Y. Zhao, L. Xiao and L. Zhang, Electrochem. Commun., 2008, 10, 1117.

48 H. Zhao, H. Jia, S. Wang, D. Xue and Z. Zheng, J. Exp. Nanosci., 2011, 6, 75.

49 G. Q. Zhang, H. B. Wu, H. E. Hoster, M. B. Chan-Park and X. W. Lou, Energy Environ. Sci., 2012, 5, 9453.

50 C. Yuan, J. Li, L. Hou, X. Zhang, L. Shen and X. W. Lou, Adv. Funct. Mater., 2012, 22, 4592.

51 G. Q. Zhang and X. W. Lou, Adv. Mater., 2013, 25, 976.

52 N. Du, Y. Xu, H. Zhang, J. Yu, C. Zhai and D. Yang, Inorg. Chem., 2011, 50, 3320.

53 H. Jiang, J. Ma and C. Li, Chem. Commun., 2012, 48, 4465.

54 S.-W. Kim, H.-W. Lee, P. Muralidharan, D.-H. Seo, W.-S. Yoon, D. K. Kim and K. Kang, Nano Res., 2011, 4, 505.

55 H. Wang, Q. Gao and L. Jiang, Small, 2011, 7, 2454.

56 C. Yuan, J. Li, L. Hou, L. Yang, L. Shen and X. Zhang, J. Mater. Chem., 2012, 22, 16084.

57 D. Zhang, Z. Tong, G. Xu, S. Li and J. Ma, Solid State Sci., 2009, 11, 113.

58 L. Zhou, D. Y. Zhao and X. W. Lou, Adv. Mater., 2012, 24, 745.

59 P. F. Teh, Y. Sharma, S. S. Pramana and M. Srinivasan, J. Mater. Chem., 2011, 21, 14999.

60 W. Luo, X. Hu, Y. Sun and Y. Huang, J. Mater. Chem., 2012, 22, 8916.

61 G. Zhang, B. Y. Xia, C. Xiao, L. Yu, X. Wang, Y. Xie and X. W. Lou, Angew. Chem., Int. Ed., 2013, 52, 8643.

62 Z. Xing, Z. Ju, J. Yang, H. Xu and Y. Qian, Nano Res., 2012, $5,477$.

63 D. Zhang, X. Zhang, X. Ni, J. Song and H. Zheng, Chem. Phys. Lett., 2006, 426, 120. 
64 G. Zhang, L. Yu, H. B. Wu, H. E. Hoster and X. W. Lou, Adv. Mater., 2012, 24, 4609.

65 J. Li, S. Xiong, X. Li and Y. Qian, J. Mater. Chem., 2012, 22, 23254.

66 S. M. Hwang, S. Y. Kim, J. G. Kim, K. J. Kim, J. W. Lee, M. S. Park, Y. J. Kim, M. Shahabuddin, Y. Yamauchi and J. H. Kim, Nanoscale, 2015, 7, 8351.

67 K. E. Sickafus and J. M. Wills, J. Am. Ceram. Soc., 1999, 82, 3279.

68 B. J. Wood, R. J. Kirkpatrick and B. Montez, Am. Mineral., 1986, 71, 999.

69 L. Schreyeck, A. Wlosik and H. Fuzellier, J. Mater. Chem., 2001, 11, 483.

70 P. Barpanda, S. K. Behera, P. K. Gupta, S. K. Pratihar and S. Bhattacharya, J. Eur. Ceram. Soc., 2006, 26, 2603.

71 A. Walsh, S.-H. Wei, Y. Yan, M. M. Al-Jassim and J. A. Turner, Phys. Rev. B: Condens. Matter Mater. Phys., 2007, 76, 165119.

72 X.-L. Xu, Z.-H. Chen, Y. Li, W.-K. Chen and J.-Q. Li, Surf. Sci., 2009, 603, 653.

73 J. Chen, X. Wu and A. Selloni, Phys. Rev. B: Condens. Matter Mater. Phys., 2011, 83, 245204.

74 P. F. Ndione, Y. Shi, V. Stevanovic, S. Lany, A. Zakutayev, P. A. Parilla, J. D. Perkins, J. J. Berry, D. S. Ginley and M. F. Toney, Adv. Funct. Mater., 2014, 24, 610.

75 N. Bahlawane, P. H. Tchoua Ngamou, V. Vannier, T. Kottke, J. Heberle and K. Kohse-Höinghaus, Phys. Chem. Chem. Phys., 2009, 11, 9224.

76 H. Wang, R. Kavanagh, Y.-L. Guo, Y. Guo, G. Lu and P. Hu, J. Catal., 2012, 296, 110.

77 H. Sun, H. M. Ang, M. O. Tadé and S. Wang, J. Mater. Chem. A, 2013, 1, 14427.

78 J. Xiao, Q. Kuang, S. Yang, F. Xiao, S. Wang and L. Guo, Sci. Rep., 2013, 3, 2300.

79 X.-Y. Yu, Q.-Q. Meng, T. Luo, Y. Jia, B. Sun, Q.-X. Li, J.-H. Liu and X.-J. Huang, Sci. Rep., 2013, 3, 2886.

80 P. Mountapmbeme Kouotou, H. Vieker, Z. Y. Tian, P. H. Tchoua Ngamou, A. El Kasmi, A. Beyer, A. Gölzhäuser and K. Kohse-Höinghaus, Catal. Sci. Technol., 2014, 4, 3359.

81 Q. Song and Z. J. Zhang, J. Am. Chem. Soc., 2004, 126, 6164.

82 S. Xiong, C. Yuan, X. Zhang, B. Xi and Y. Qian, Chem. - Eur. J., 2009, 15, 5320.

83 K. Cheng, F. Yang, G. Wang, J. Yin and D. Cao, J. Mater. Chem. A, 2013, 1, 1669.

84 C. Yuan, H. B. Wu, Y. Xie and X. W. Lou, Angew. Chem., Int. Ed., 2014, 53, 1488.

85 D. U. Lee, J. Scott, H. W. Park, S. Abureden, J.-Y. Choi and Z. Chen, Electrochem. Commun., 2014, 43, 109.

86 H. S. Jadhav, R. S. Kalubarme, C.-N. Park, J. Kim and C.-J. Park, Nanoscale, 2014, 6, 10071.

87 G. Meng, Q. Yang, Y. Wang, X. Sun and J. Liu, RSC Adv., 2014, 4, 57804.

88 Y. Zhou, Y. Liu, W. Zhao, H. Wang, B. Li, X. Zhou and H. Shen, Sci. Rep., 2015, 5, 11584.

89 C. Li, X. Han, F. Cheng, Y. Hu, C. Chen and J. Chen, Nat. Commun., 2015, 6, 7345.
90 J. Rosen, G. S. Hutchings and F. Jiao, J. Am. Chem. Soc., 2013, 135, 4516.

91 J. Zhu and Q. Gao, Microporous Mesoporous Mater., 2009, 124, 144.

92 H. B. Wu, H. Pang and X. W. Lou, Energy Environ. Sci., 2013, 6, 3619.

93 R. Wu, X. Qian, K. Zhou, J. Wei, J. Lou and P. M. Ajayan, ACS Nano, 2014, 8, 6297.

94 H. Guo, L. Liu, T. Li, W. Chen, J. Liu, Y. Guo and Y. Guo, Nanoscale, 2014, 6, 5491.

95 J. G. Guan, F. Z. Mou, Z. G. Sun and W. D. Shi, Chem. Commun., 2010, 46, 6605.

96 L. Zhou, H. B. Wu, T. Zhu and X. W. Lou, J. Mater. Chem., 2012, 22, 827.

97 L. Shen, L. Yu, X.-Y. Yu, X. Zhang and X. W. Lou, Angew. Chem., Int. Ed., 2015, 54, 1868.

98 M. Armand and J.-M. Tarascon, Nature, 2008, 451, 652.

99 Y.-G. Guo, J.-S. Hu and L.-J. Wan, Adv. Mater., 2008, 20, 2878.

100 H. Chen, T. N. Cong, W. Yang, C. Tan, Y. Li and Y. Ding, Prog. Nat. Sci., 2009, 19, 291.

101 S. Arico, P. Bruce, B. Scrosati, J.-M. Tarascon and W. V. Schalkwijk, Nat. Mater., 2005, 4, 366.

102 J. Christensen, P. Albertus, R. S. Sanchez-Carrera, Y. Lohmann, B. Kozinsky, R. Liedtke, J. Ahmed and A. Kojic, J. Electrochem. Soc., 2012, 159, R1.

103 M. S. Park, S. B. Ma, D. J. Lee, D. Im, S.-G. Doo and O. Yamamoto, Sci. Rep., 2014, 4, 3815.

104 G. Girishkumar, B. McCloskey, A. C. Luntz, S. Swanson and W. Wilcke, J. Phys. Chem. Lett., 2010, 1, 2193.

105 J.-S. Lee, S. T. Kim, R. Cao, N.-S. Choi, M. Liu, K.-T. Lee and J. Cho, Adv. Energy Mater., 2011, 1, 34.

106 F. Li, T. Zhang and H. Zhou, Energy Environ. Sci., 2013, 6, 1125.

107 M. A. Rahman, X. Wang and C. Wen, J. Electrochem. Soc., 2013, 160, A1759.

108 J. Lu, L. Li, J.-B. Park, Y.-K. Sun, F. Wu and K. Amine, Chem. Rev., 2014, 114, 5611.

109 Y. Li and H. Dai, Chem. Soc. Rev., 2014, 43, 5257.

110 V. Neburchilov, H. Wang, J. J. Martin and W. Qu, J. Power Sources, 2010, 195, 1271.

111 F. Cheng and J. Chen, Chem. Soc. Rev., 2012, 41, 2172.

112 Z.-L. Wang, D. Xu, J.-J. Xu and X.-B. Zhang, Chem. Soc. Rev., 2014, 43, 7746.

113 Y. Xu, A. V. Ruban and M. Mavrikakis, J. Am. Chem. Soc., 2004, 125, 4717.

114 C. Wang, H. Daimon, Y. Lee, J. Kim and S. Sun, J. Am. Chem. Soc., 2007, 129, 6974.

115 Y. Lee, J. Suntivich, K. J. May, E. E. Perry and Y. Shao-Horn, J. Phys. Chem. Lett., 2012, 3, 399.

116 Y. Tang, H. Qiao, H. Wang and P. Tao, J. Mater. Chem. A, 2013, 1, 12512.

117 K.-N. Jung, J.-I. Lee, W. B. Im, S. Yoon, K.-H. Shin and J.-W. Lee, Chem. Commun., 2012, 48, 9406.

118 K.-N. Jung, J.-I. Lee, S. Yoon, S.-H. Yeon, W. Chang, K.-H. Shin and J.-W. Lee, J. Mater. Chem., 2012, 22, 21845. 
119 S. Malkhandi, B. Yang, A. K. Manohar, A. Manivannan, G. K. Surya Prakash and S. R. Narayanan, J. Phys. Chem. Lett., 2012, 3, 967.

120 Z. Chen, A. Yu, D. Higgins, H. Li, H. Wang and Z. Chen, Nano Lett., 2012, 12, 1946.

121 S. H. Oh, R. Black, E. Pomerantseva, J.-H. Lee and L. F. Nazar, Nat. Chem., 2012, 4, 1004.

122 K.-N. Jung, J.-H. Jung, W. B. Im, S. Yoon, K.-H. Shin and J.-W. Lee, ACS Appl. Mater. Interfaces, 2013, 5, 9902.

123 J.-J. Xu, D. Xu, Z.-L. Wang, H.-G. Wang, L.-L. Zhang and X.-B. Zhang, Angew. Chem., Int. Ed., 2013, 52, 3887.

124 G. Du, X. Liu, Y. Zong, T. S. A. Hor, A. Yu and Z. Liu, Nanoscale, 2013, 5, 4657.

125 X. Han, Y. Hu, J. Yang, F. Cheng and J. Chen, Chem. Commun., 2014, 50, 1497.

126 J.-J. Xu, Z.-L. Wang, D. Xu, F.-Z. Meng and X.-B. Zhang, Energy Environ. Sci., 2014, 7, 2213.

127 E. Rios, J.-L. Gautier, G. Poillerat and P. Chartier, Electrochim. Acta, 1998, 44, 1491.

128 S. Ma, L. Sun, L. Cong, X. Gao, C. Yao, X. Guo, L. Tai, P. Mei, Y. Zeng, H. Xie and R. Wang, J. Phys. Chem. C, 2013, 117, 25890.

129 K.-N. Jung, S. M. Hwang, M.-S. Park, K. J. Kim, J.-G. Kim, S. X. Dou, J. H. Kim and J.-W. Lee, Sci. Rep., 2015, 5, 7665.

130 M. Prabu, K. Ketpang and S. Shanmugam, Nanoscale, 2014, 6, 3173.

131 C. O. Laoire, S. Mukerjee, K. M. Abraham, E. J. Plichta and M. A. Hendrickson, J. Phys. Chem. C, 2009, 113, 20127.

132 Y.-C. Lu, D. G. Kwabi, K. P. C. Yao, J. R. Harding, J. Zhou, L. Zuin and Y. Shao-Horn, Energy Environ. Sci., 2011, 4, 2999.

133 B. M. Gallant, R. R. Mitchell, D. G. Kwabi, J. Zhou, L. Zuin, C. V. Thompson and Y. Shao-Horn, J. Phys. Chem. C, 2012, 116, 20800.

134 J. Hou, M. Yang, M. W. Ellis, R. B. Moore and B. Yi, Phys. Chem. Chem. Phys., 2012, 14, 13487.

135 M. D. Bhatt, H. Geaney, M. Nolan and C. O'Dwyer, Phys. Chem. Chem. Phys., 2014, 16, 12093.

136 A. Débart, J. L. Bao, G. Armstrong and P. G. Bruce, J. Power Sources, 2007, 174, 1177.

137 V. Giordani, S. A. Freunberger, P. G. Bruce, J.-M. Tarascon and D. Larcher, Electrochem. Solid-State Lett., 2010, 13, A180.

138 Y. Cui, Z. Wen, S. Sun, Y. Lu and J. Jin, Solid State Ionics, 2012, 225, 598.

139 C. Sun, F. Li, C. Ma, Y. Wang, Y. Ren, W. Yang, Z. Ma, J. Li, Y. Chen, Y. Kim and L. Chen, J. Mater. Chem. A, 2014, 2, 7188.

140 R. Black, J.-H. Lee, B. Adams, C. A. Mims and L. F. Nazar, Angew. Chem., Int. Ed., 2012, 52, 392.

141 J. Zhu, X. Ren, J. Liu, W. Zhang and Z. Wen, ACS Catal., 2015, 5, 73.

142 A. Riaz, K.-N. Jung, W. Chang, S.-B. Lee, T.-H. Lim, S.-J. Park, R.-H. Song, S. Yoon, K.-H. Shin and J.-W. Lee, Chem. Commun., 2013, 49, 5984.

143 A. Riaz, K.-N. Jung, W. Chang, K.-H. Shin and J.-W. Lee, ACS Appl. Mater. Interfaces, 2014, 6, 17815.

144 L. J. Hardwick and P. G. Bruce, Curr. Opin. Solid State Mater. Sci., 2012, 16, 178.
145 J. Zhang, L. Wang, L. Xu, X. Ge, X. Zhao, M. Lai, Z. Liu and W. Chen, Nanoscale, 2015, 7, 720.

146 D. Su, S. Dou and G. Wang, Sci. Rep., 2014, 4, 5767.

147 B. Sun, J. Zhang, P. Munroe, H.-J. Ahn and G. Wang, Electrochem. Commun., 2013, 31, 88.

148 S. G. Mohamed, Y.-Q. Tsai, C.-J. Chen, Y.-T. Tsai, T.-F. Hung, W.-S. Chang and R.-S. Liu, ACS Appl. Mater. Interfaces, 2015, 7, 12038.

149 W.-M. Liu, T.-T. Gao, Y. Yang, Q. Sun and Z.-W. Fu, Phys. Chem. Chem. Phys., 2013, 15, 15806.

150 W.-H. Ryu, T.-H. Yoon, S. H. Song, S. Jeon, Y.-J. Park and I.-D. Kim, Nano Lett., 2013, 13, 4190.

151 L. Zhang, S. Zhang, K. Zhang, G. Xu, X. He, S. Dong, Z. Liu, C. Huang, L. Gu and G. Cui, Chem. Commun., 2013, 49, 3540 .

152 G. Zhao, Z. Xu and K. Sun, J. Mater. Chem. A, 2013, 1, 12862 .

153 T.-F. Hung, S. G. Mohamed, C.-C. Shen, Y.-Q. Tsai, W.-S. Chang and R.-S. Liu, Nanoscale, 2013, 5, 12115.

154 F. Wang, Z. Wen, C. Shen, K. Rui, X. Wu and C. Chen, J. Mater. Chem. A, 2015, 3, 7600.

155 Y. Li, K. Guo, J. Li, X. Dong, T. Yuan, X. Li and H. Yang, ACS Appl. Mater. Interfaces, 2014, 6, 20949.

156 F. Cheng, H. Wang, Z. Zhu, Y. Wang, T. Zhang, Z. Tao and J. Chen, Energy Environ. Sci., 2011, 4, 3668.

157 X. Li, F. Cheng, B. Guo and J. Chen, J. Phys. Chem. B, 2005, 109, 14017.

158 F. Jiao, J. Bao, A. H. Hill and P. G. Bruce, Angew. Chem., Int. Ed., 2008, 47, 9711.

159 K. Kim, P. Muralidharan, H.-W. Lee, R. Ruffo, Y. Yang, C. K. Chan, H. Peng, R. A. Huggings and Y. Cui, Nano Lett., 2008, 8, 3948.

160 T. J. Patey, R. Buchel, M. Nakayama and P. Novak, Phys. Chem. Chem. Phys., 2009, 11, 3756.

161 Y. Zhang, H.-C. Shin, J. Dong and M. Liu, Solid State Ionics, 2004, 171, 25.

162 Y. Deng, Y. Zhou, Z. Shi, X. Zhou, X. Quan and G. Chen, J. Mater. Chem. A, 2013, 1, 8170.

163 J. Wang, L. Shen, H. Li, B. Ding, P. Nie, H. Dou and X. Zhang, J. Alloys Compd., 2014, 587, 171.

164 L. Hu, H. Zhong, X. Zheng, Y. Huang, P. Zhang and Q. Chen, Sci. Rep., 2012, 2, 986.

165 J. Haetge, P. Hartmann, K. Brezesinski, J. Janek and T. Brezesinski, Chem. Mater., 2011, 23, 4384.

166 Z. Yu, L. Tetard, L. Zhai and J. Thomas, Energy Environ. Sci., 2015, 8, 702.

167 D. Chen, Q. Wang, R. Wang and G. Shen, J. Mater. Chem. A, 2015, 3, 10158.

168 C. Yuan, J. Li, L. Hou, J. Lin, X. Zhang and S. Xiong, J. Mater. Chem. A, 2013, 1, 11145.

169 I. Shakir, M. Sarfraz, U. A. Rana, M. Nadeem and M. A. Al-Shaikh, RSC Adv., 2013, 3, 21386.

170 J. Du, G. Zhou, H. Zhang, C. Cheng, J. Ma, W. Wei, L. Chen and T. Wang, ACS Appl. Mater. Interfaces, 2013, 5, 7405.

171 X. Wang, S. Y. Xiao, X. W. Gao, Y. S. Zhu, H. P. Zhang, Y. P. Wu and R. Holze, J. Power Sources, 2013, 242, 560. 
172 M. S. Whittingham, MRS Bull., 2008, 33, 411.

173 R. R. Salunkhe, J. Tang, Y. Kamachi, T. Nakato, J. H. Kim and Y. Yamauchi, ACS Nano, 2015, 9, 6288.

174 V. Malgras, Q. Ji, Y. Kamachi, T. Mori, F.-K. Shieh, K. C.-W. Wu, K. Ariga and Y. Yamauchi, Bull. Chem. Soc. Jpn., 2015, 88, 1171.

175 K. Ariga, J. Inorg. Organomet. Polym., 2015, 25, 177.

176 J. Kim, B. Kim, C. Anand, A. Mano, J. S. M. Zaidi, K. Ariga, J. You, A. Vinu and E. Kim, Angew. Chem., Int. Ed., 2015, 54, 8407.
177 K. Ariga, Q. Ji, W. Nakanishi, J. P. Hill and M. Aono, Mater. Horiz., 2015, 2, 406.

178 W. Chaikittisilp, K. Muraoka, Q. Ji, K. Ariga and Y. Yamauchi, J. Mater. Chem. A, 2014, 2, 12096.

179 M. Aono and K. Ariga, Adv. Mater., 2015, DOI: 10.1002/ adma.201502868.

180 W. Chaikittisilp, N. L. Torad, C. Li, M. Imura, N. Suzuki, S. Ishihara, K. Ariga and Y. Yamauchi, Chem. - Eur. J., 2014, 20, 4217. 